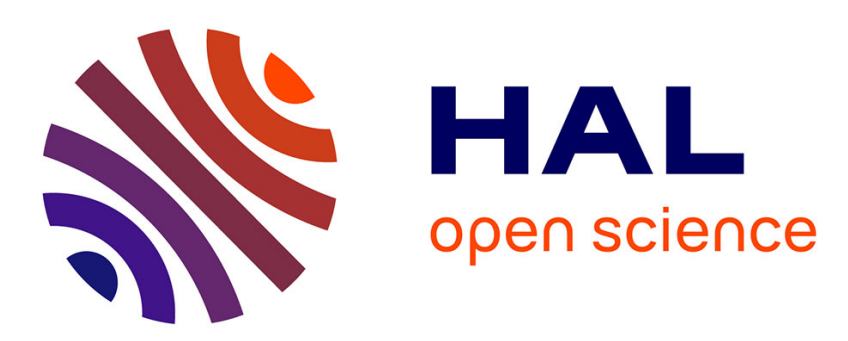

\title{
Surface albedo spectral properties of geologically interesting areas on Titan
}

\author{
A. Solomonidou, M. Hirtzig, A. Coustenis, E. Bratsolis, S. Le Mouélic, S. \\ Rodriguez, K. Stephan, P. Drossart, C. Sotin, R. Jaumann, et al.
}

\section{- To cite this version:}

A. Solomonidou, M. Hirtzig, A. Coustenis, E. Bratsolis, S. Le Mouélic, et al.. Surface albedo spectral properties of geologically interesting areas on Titan. Journal of Geophysical Research. Planets, 2014, 119 (8), pp.1729-1747. 10.1002/2014JE004634 . hal-02544482

\section{HAL Id: hal-02544482 \\ https://hal.science/hal-02544482}

Submitted on 2 Jan 2022

HAL is a multi-disciplinary open access archive for the deposit and dissemination of scientific research documents, whether they are published or not. The documents may come from teaching and research institutions in France or abroad, or from public or private research centers.
L'archive ouverte pluridisciplinaire HAL, est destinée au dépôt et à la diffusion de documents scientifiques de niveau recherche, publiés ou non, émanant des établissements d'enseignement et de recherche français ou étrangers, des laboratoires publics ou privés. 


\section{Journal of Geophysical Research: Planets}

\section{RESEARCH ARTICLE \\ 10.1002/2014JE004634 \\ Surface albedo spectral properties of geologically interesting areas on Titan}

Key Points:

- Study of distinct regions in Titan's Tui and Hotei Regio and Sotra Patera

- Surface albedos of these regions with an updated radiative transfer code

- Spectral behavior of the bright regions and implications for their nature

Correspondence to:

A. Solomonidou,

Anezina.Solomonidou@jpl.nasa.gov

\section{Citation:}

Solomonidou, A., et al. (2014), Surface albedo spectral properties of geologically interesting areas on Titan, J. Geophys. Res. Planets, 119, 1729-1747, doi:10.1002/2014JE004634.

Received 10 MAR 2014 Accepted 1 JUL 2014

Accepted article online 3 JUL 2014

Published online 1 AUG 2014 Concordia University, Montreal, Quebec, Canada

\author{
A. Solomonidou ${ }^{1,2}$, M. Hirtzig ${ }^{2,3}$, A. Coustenis ${ }^{2}$, E. Bratsolis ${ }^{4}$, S. Le Mouélic ${ }^{5}$, S. Rodriguez ${ }^{6}$, K. Stephan ${ }^{7}$, \\ P. Drossart ${ }^{2}$, C. Sotin ${ }^{1}$, R. Jaumann ${ }^{7}$, R. H. Brown ${ }^{8}$, K. Kyriakopoulos ${ }^{9}$, R. M. C. Lopes ${ }^{1}$, G. Bampasidis ${ }^{2,4}$, \\ K. Stamatelopoulou-Seymour ${ }^{10,11}$, and X. Moussas ${ }^{4}$
}

${ }^{1}$ Jet Propulsion Laboratory, California Institute of Technology, Pasadena, California, USA, ${ }^{2}$ LESIA-Observatoire de Paris, CNRS, UPMC University, Paris VI-Paris Diderot University, Meudon, France, ${ }^{3}$ Fondation "La main à la pâte", Montrouge, France, ${ }^{4}$ Department of Physics, University of Athens, Athens, Greece, ${ }^{5}$ Laboratoire Planétologie et Géodynamique, LPGNantes, CNRS UMR 6112, Université de Nantes, Nantes, France, 'aboratoire AIM, Paris VII-Paris Diderot University/ CNRS/CEA-Saclay, DSM/IRFU/SAp, Paris, France, ${ }^{7}$ Institute of Planetary Research, DLR, Berlin, Germany, ${ }^{8}$ Lunar and Planetary Laboratory, University of Arizona, Tucson, Arizona, United States, ${ }^{9}$ Department of Geology and Geoenvironment, University of Athens, Athens, Greece, ${ }^{10}$ Department of Geology, University of Patras, Patras, Greece, ${ }^{11}$ Department of Geography,

Abstract We investigate the nature and possible formation processes of three areas on Titan's surface which have been suggested as geologically interesting: Hotei Regio, Tui Regio, and Sotra Patera. We also reanalyze the spectral characteristics of the Huygens Landing Site. We apply a statistical Principal Component Analysis (PCA) and a radiative transfer (RT) method on the Visual and Infrared Mapping Spectrometer Datacubes in order to retrieve the surface albedo of distinct spectral units in the near infrared. We have been able to exploit only a subset of the currently available Hotei Regio data, which are, in general, not optimal in terms of geometry for an analysis with a plane-parallel RT code. Our inferred surface albedos present generally higher values from 1 to $2 \mu \mathrm{m}$ and lower ones at 0.94 and in the $2.6-5 \mu \mathrm{m}$ region. The Regions of Interest (Rols) within Hotei Regio, Tui Regio, and Sotra Patera are always significantly brighter than the surrounding areas. The largest variations are found longward of $2 \mu \mathrm{m}$ and mainly at $5 \mu \mathrm{m}$. This higher surface albedo with respect to the surrounding area and, in general, the fact that the spectral behavior is different for each of these areas, is probably indicative of diverse chemical compositions and origins. We compare the spectral albedos with some suggested surface candidates on Titan (such as $\mathrm{H}_{2} \mathrm{O}, \mathrm{CO}_{2}$, and $\mathrm{CH}_{4}$ ices, as well as tholin) and discuss possible chemical composition variations as well as other interpretations.

\section{Context and Description of Observations}

Titan, Saturn's largest natural satellite, is a key area for planetary research due to its complex atmosphere and surface. The data collected from the Cassini-Huygens space mission, which from 2004 until today thoroughly explores the Saturnian system, indicate that Titan offers a unique opportunity to study the internal and surface processes of an outer solar system moon in relation to Earth-like geological features.

Multiple flybys performed by the Cassini-Huygens mission revealed an intriguing surface both in terms of morphology and composition. Data retrieved from the Cassini Visual and Infrared Mapping Spectrometer (VIMS) [Brown et al., 2004], the Synthetic Aperture Radar (SAR) [Elachi et al., 2004], and the Imaging Science Subsystem (ISS) [Porco et al., 2004] showed the presence of geologically distinct surface areas whose exact nature and composition remains largely unknown. The Huygens probe delivered the first "ground truth" on one location only on Titan, at its landing site $\left(10^{\circ} \mathrm{S}, 192^{\circ} \mathrm{W}\right)$, including large surface panoramas and local topography estimations with the Descent Imager/Spectral Radiometer (DISR) [Tomasko et al., 2005], as well as a number of mechanical properties of the surface (e.g., particle size, stickiness, roughness measurements) with the Surface Science Package (SSP) [Zarnecki et al., 2005]. In addition, the Huygens Atmospheric Structure Instrument (HASI) [Fulchignoni et al., 2005] measured the local pressure and temperature and the dielectric properties of the surface material while direct atmospheric composition measurements were provided from the Gas Chromatograph Mass Spectrometer (GCMS), including altitude profiles of several constituents [Niemann et al., 2005]. 


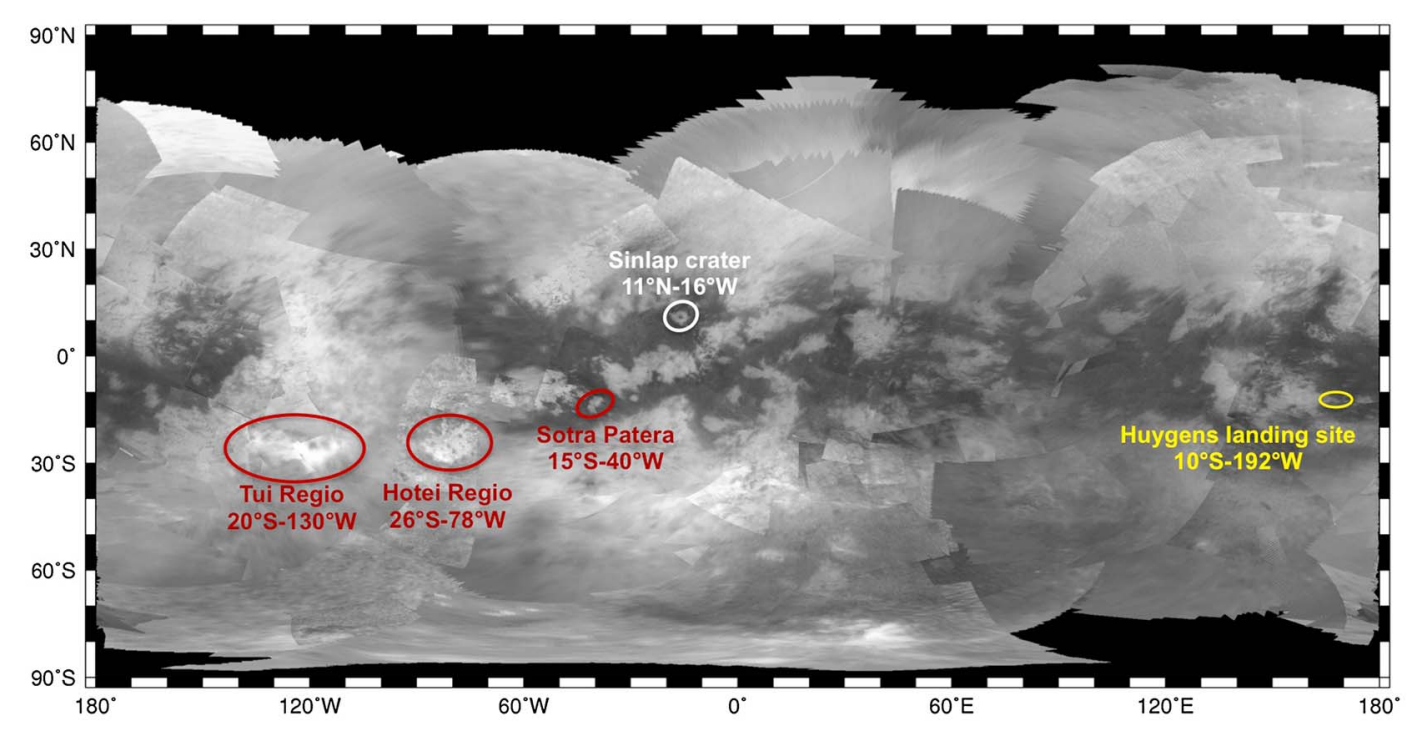

Figure 1. Map of Titan from VIMS data at $2 \mu \mathrm{m}$ from October 2004 up to June 2010. From left to right the red ovals include the candidate cryovolcanic areas called Tui Regio, Hotei Regio, and Sotra Patera. In yellow is the reference area of the Huygens landing site. Also visible is the Sinlap crater area (white oval). Background map is from Le Mouélic et al. [2012].

The large variety of geologically interesting areas on Titan includes morphotectonic features [Solomonidou et al., 2013] that are possibly formed due to tectonic-like processes and are/were subsequently subjected to exogenous processes, surficial and/or atmospheric. Such features are mountains [e.g., Radebaugh et al., 2007; Lorenz et al., 2011], ridges [Soderblom et al., 2007a; Mitri et al., 2010], faults [e.g., Radebaugh et al., 2011], and canyons [e.g., Lopes et al., 2010]. In addition, Titan exhibits fluvial [e.g., Lorenz et al., 2008; Langhans et al., 2012] and aeolian features [e.g., Radebaugh et al., 2009] like river systems, lakes [Stofan et al., 2007; Sotin et al., 2012], and dunes [Lorenz et al., 2006; Radebaugh et al., 2009; Rodriguez et al., 2014]. Finally, impact features [Wood et al., 2010; Buratti et al., 2012; Burr et al., 2013; Neish et al., 2013] are present, as well as volcanic-like features that are possibly the result of cryovolcanic and tectonic activity [e.g., Sotin et al., 2005; Lopes et al., 2007, 2013; Soderblom et al., 2009; Furfaro et al., 2010; Solomonidou et al., 2013].

Furthermore, the analyses of Titan's geological environment with Cassini-Huygens data suggest surface compositional variations [Barnes et al., 2005, 2006, 2007a, 2007b, 2008, 2011; Sotin et al., 2005; Rodriguez et al., 2006; Le Mouélic et al., 2008, 2012; McCord et al., 2008; Soderblom et al., 2007b, 2009; Nelson et al., 2009a, 2009b; Wall et al., 2009], including a diversity of proposed surface formational mechanisms [Tobie et al., 2005, 2006; Fortes et al., 2007; Zhong et al., 2009; Lopes et al., 2010, 2013]. Indeed, some Titan surface areas in particular have been highlighted by several authors as presenting special characteristics, either because of their reflectance properties (determined by spectroimagery and imagery alone with VIMS and ISS) and/or because of their morphological aspects (from Cassini Radar (RADAR) data essentially).

Figure 1 highlights Tui Regio, Hotei Regio, and Sotra Patera (in this paper by "Sotra Patera" we refer to the general area which includes the Sotra Patera, Mohini Fluctus, and Doom Mons regions, as defined in Lopes et al. [2013]), three geologically interesting areas on Titan that have been proposed by some authors as potential cryovolcanic candidates. All three of them are located in the near-equatorial zone between $15^{\circ} \mathrm{S}$ and $30^{\circ} \mathrm{S}$, an area which may be an extensive zone of crustal weakness (i.e., a tectonic fractured layer or feature (e.g., a fault) where the rock mass properties are significantly poorer (based on the Rock Mass Rating (RMR) classification [Bieniawski, 1989]) than in the surrounding materials [Soderblom et al., 2009; Solomonidou et al., 2013]).

Hotei Regio $\left(26^{\circ} \mathrm{S}, 78^{\circ} \mathrm{W}\right.$, Figure 1$)$, for instance, has been suggested to have a distinct surface composition by Barnes et al. [2005] and to be anomalously bright at $5 \mu \mathrm{m}$, connected perhaps to a geophysical phenomenon such as deposition of material or weathering. Soderblom et al. [2007b, 2009] studied Hotei Regio's VIMS data color variations and correlation with morphological features seen in SAR images and suggested a possible influence of complex geological processes, like tectonism and cryovolcanism, that remained active until very recent geological times (possibly less than $10^{4}$ years). Moreover, Nelson et al. [2009a] reported that Hotei 
Regio showed changes in the near-infrared reflectance from 2004 to 2006, which could be linked to cryovolcanism and ammonia deposits. The Cassini SAR images indicate that the area is a low basin surrounded by higher terrains with possible calderas [Soderblom et al., 2009], fault features, and extensive cryovolcanic flows [Lopes et al., 2013]. Soderblom et al. [2009] have studied the area and indicated significant geological features that resemble terrestrial volcanoes. These are viscous flow-like figures, a $1 \mathrm{~km}$ in height mountainous (ridge-like) terrain that surrounds the basin, as well as dendritic channels, caldera-like features, dark blue patches (in VIMS RGB composite coloring, with relative absorption signatures at 1.59 and $2.03 \mu \mathrm{m}$ ) likely related to water ice-rich exposed terrains [Rodriguez et al., 2006] and possibly alluvial deposits. An additional major structure located at the southern margin of Hotei Regio is the bright arc named Hotei Arcus, which Barnes et al. [2005] characterized as a possible heavily eroded crater. Geologically, this leads to the assumption that different types of processes like cryovolcanism and/or aeolian/fluvial erosion may have acted upon and/or interplayed in the same feature.

Tui Regio $\left(20^{\circ} \mathrm{S}-130^{\circ} \mathrm{W}\right.$, Figure 1$)$ is a feature $150 \mathrm{~km}$ wide and extends for $1500 \mathrm{~km}$ in an east-west direction [Barnes et al., 2005, 2006; Wall et al., 2009; Brown et al., 2011]. The analysis of Cassini ISS and mainly of VIMS data [Barnes et al., 2006, 2007b] suggest that the area is a massive flow field since at least three long lobate spectrally distinct tendrils [Barnes et al., 2006] have been observed and have possibly being effused from a main point like a caldera-like structure, fracture or fissure. It has also been characterized by McCord et al. [2008] as a spectrally distinct unit in composition, especially because of its anomalous brightness at $5 \mu \mathrm{m}$ which has been confirmed using updated VIMS maps from Vixie et al. [2012]. Barnes et al. [2006] suggested that a flow-like feature at the western part of Tui Regio could present cryovolcanic activity from the study of its geometry, relative age, and chemical composition. In fact, a number of studies suggest that the whole area may be geologically young and that the resembling lava flows could be deposits of cryovolcanic activity.

Alternative studies based on estimations of Titan's topography for Tui Regio and Hotei Regio suggest that both areas could be sites of large low-latitude paleolakes [Moore and Howard, 2010]. In addition, Barnes et al. [2011] suggested the presence of dry lakebeds at Titan's north pole with spectral characteristics similar to Tui Regio and Hotei Regio, implying a common evaporitic origin (i.e., deposits due to dissolution of chemical solids that precipitate out of a mixture as their liquid solvent evaporates). Moore and Pappalardo [2011] also suggested that the areas are the result of exogenic deposits, either fluvial or lacustrine.

In a recent investigation of Cassini VIMS and RADAR data, Lopes et al. [2013] also identified Tui Regio and Hotei Regio, along with another region now called Sotra Patera (formerly Sotra Facula, $15^{\circ} \mathrm{S}, 40^{\circ} \mathrm{W}$, Figure 1 ), as geologically compelling areas, suggesting again the possibility of cryovolcanic activity. Sotra Patera has been identified as an additional potential cryovolcanic terrain [Lopes et al., 2010, 2013]. Morphologically, it consists of two mountains, one of which is the highest known mountain on Titan named Doom Mons $\left(40^{\circ} \mathrm{W}, 15^{\circ} \mathrm{S}\right)$, while the other one is Erebor Mons $\left(35^{\circ} \mathrm{W}, 5^{\circ} \mathrm{S}\right)$. Additionally, lobate flow deposits named Mohini Fluctus $\left(12^{\circ} \mathrm{S}, 39^{\circ} \mathrm{W}\right)$ seem to emerge from Doom Mons while Sotra Patera is a deep noncircular depression that is considered as the deepest local depression identified on Titan [Kirk et al., 2010; Lopes et al., 2010, 2013].

In addition to their morphological and geological interesting properties, these areas have also been considered early on as having different surface chemical composition from the surrounding terrain. Many suggestions have been made so far regarding the chemical composition of the bright regions of Tui Regio and Hotei Regio. Tui Regio was analyzed in Hirtzig et al. [2013] and Sotra Patera by Lopes et al. [2013] in terms of morphology. Barnes et al. [2005] and McCord et al. [2006, 2008] proposed fine-grained recent deposits of $\mathrm{CO}_{2}$ ice as a possible constituent for the bright regions of Tui Regio and Hotei Regio. However, Soderblom et al. [2009] noted a shifting of the $5 \mu \mathrm{m}$ feature from the laboratory $\mathrm{CO}_{2}$ measurements that reduced the interest of this hypothesis. On the other hand, Fortes et al. [2007] suggested ammonium sulfate as a candidate material for the $5 \mu \mathrm{m}$ bright regions and Nelson et al. [2009a] proposed depositions of ammonia as a possible explanation for Hotei Regio's reflectivity. On the whole, suggestions for the presence of some simple ices, tholins, organics, and other material on Titan's surface in relation to atmospheric deposits or to ejections from an internal liquid water-ammonia ocean. In support of that latter theory, a recent study by Sohl et al. [2014] shows that the global pattern of maximum tidal stresses of Titan is consistent with the location of the cryovolcanic candidate areas, in the $15^{\circ} \mathrm{S}-30^{\circ} \mathrm{S}$ latitudinal zone, as a possible characteristic of active regions that overlay a zone of crustal weakness [e.g., Head et al., 2002; Rehman, 2010]. Thus, a connection between the interior and the surface seems plausible. 
In this study we focus on the aforementioned spectrally and geologically interesting areas (Hotei Regio, Tui Regio, and Sotra Patera) by using a new approach which allows us to deal with the limitations set on Titan surface studies due to the presence of its thick atmosphere. Indeed, all inferences of surface properties on Titan need to first account for the atmospheric contribution in the data. We use here a radiative transfer code (RT) as described in section 2.3 that includes the most recent evaluations of the aerosol and methane opacity characteristics. We start by first applying a statistical Principal Component Analysis (PCA) method validated against results obtained for the Sinlap crater $\left(16^{\circ} \mathrm{W}, 11^{\circ} \mathrm{N}\right.$, Figure 1) by Le Mouélic et al. [2008], in order to extract a number of different spectral units in these areas. We make a specific pixel selection of regions that we call "Regions of Interest-Rols" for each datacube of our study areas. These Rols are portions of the distinct spectral units that are defined from the application of the Principal Component Analysis. We thus select one Rol from within Hotei Regio, Tui Regio, and Sotra Patera (as defined in Barnes et al. [2006] for Tui and Hotei and in Lopes et al. [2010] for Sotra), and one from the surrounding regions that PCA shows to be of a different spectral unit than the main study areas. These Rols are then analyzed with a radiative transfer code that includes updates on spectroscopic and haze parameters (as described in detail in Hirtzig et al. [2013]). Hence, it represents an improvement with respect to previous investigations of Titan's lower atmosphere and surface from VIMS data that were either not using a full radiative transfer code for the atmosphere but approximations or that did not include the most recent parameters (as in Griffith et al. [2012]). Thus, this method allows us to derive the I/F of the specific regions, separate the atmospheric and surface components, determine the surface albedo, and hence retrieve information on both the lower atmospheric and surface properties thus complementing previous studies and providing new results on the haze and the absolute surface albedo of these areas. Furthermore, we compare and calibrate our results from the three areas with analogous inferences for the Huygens landing site and discuss them in the context of previous publications. We aim to compare the inferences on the surface spectrum of Hotei, Tui, and Sotra with the surrounding areas and to look for possible interpretations as concerns the surface composition or the surface alteration processes by comparing with existing spectra of candidate surface constituents and with other results on surface morphology.

\section{Analysis}

\subsection{VIMS Data}

The Cassini/VIMS instrument [Brown et al., 2004] consists of two cameras, a push-broom mapping spectrometer that studies visible light (VIMS-VIS) and a whiskbroom mapping spectrometer for infrared light (VIMS-IR). VIMS image cubes contain information in 352 different wavelengths covering the spectral range from the ultraviolet to the midinfrared. The visible channel produces hyperspectral images in the $0.3-1.05 \mu \mathrm{m}$ spectral range over 96 spectral bands. The infrared channel covers the 0.89-5.1 $\mu \mathrm{m}$ range over 256 spectral bands. The spectral resolution (Full Width At Half Maximum, FWHM) varies from $13 \mathrm{~nm}$ below $2.0 \mu \mathrm{m}$, to $22 \mathrm{~nm}$ at $4.2 \mu \mathrm{m}$, and $18 \mathrm{~nm}$ at $4.8 \mu \mathrm{m}$. The calibration procedure of the infrared channel is described in Brown et al. [2004], McCord et al. [2006], and Barnes et al. [2007b]. For more details on the instrument, the reader is referred to Brown et al. [2004].

In this study we have used VIMS data retrieved from five different Cassini flybys, each representing a different area on Titan's surface. The characteristics of the five VIMS cubes that we use here, one for Huygens Landing site (HLS), the Sinlap crater, Hotei Regio, Tui Regio, and Sotra Patera, are summarized in Table 1.

We make a special note at this point for Hotei Regio, for which it was difficult to find a datacube compatible with our RT method and where we then had to test a total of 16 datacubes without getting in the detailed analysis, before choosing the one presented here, which is among the best in terms of overall quality. Indeed we found that when compared to the observations of the other areas, most of the Hotei Regio datacubes suffer from some combination of larger incidence and phase angles, and worse spatial resolution at the time of the data acquisition. These more unfavorable parameters play a role in the radiative transfer (RT) calculations with our code which functions in a plane-parallel approximation and is incompatible with a combination of angles higher than $60^{\circ}$ for incidence or emergence. As a consequence, we were not able to retrieve results from all the 16 Hotei datacubes: 11 returned an adequate result, while the other 5 failed. This could be remedied in the future with better quality observations of this area, or with a more sophisticated code. The datacube we process here (Table 1, Hotei Regio) represents the Hotei Regio area in good resolution so that the use of PCA and the selection of Rols is possible and furthermore our RT code 
Table 1. Cassini/VIMS Datacube Observations ${ }^{a}$

Observation

\begin{tabular}{|c|c|c|c|c|c|c|c|}
\hline \multicolumn{5}{|l|}{ Unservation } & \multicolumn{3}{|c|}{ Angles (aeg) } \\
\hline Area/Coordinates & Flyby/Date/Datacube & $\begin{array}{c}\text { Distance } \\
\text { Cassini-Surface } \\
(\mathrm{km})\end{array}$ & $\begin{array}{l}\text { Spatial Resolution } \\
(\mathrm{km} / \text { pixel })\end{array}$ & $\begin{array}{l}\text { Exposure } \\
\text { Time (s) }\end{array}$ & $\begin{array}{l}\text { Incidence } \\
\text { (i) }\end{array}$ & $\begin{array}{l}\text { Emergence } \\
\qquad(e)\end{array}$ & $\begin{array}{l}\text { Phase } \\
\qquad(\theta)\end{array}$ \\
\hline $\mathrm{HLS} / 10^{\circ} \mathrm{S}, 192^{\circ} \mathrm{W}$ & TB/December 2004/CM_1481624349 & 34,110 & 15 & 160 & 36 & 34 & 18 \\
\hline Sinlap $/ 11^{\circ} \mathrm{N}, 16^{\circ} \mathrm{W}$ & T13/April 2006/CM_1525118253 & 27,180 & 14 & 68 & 42 & 12 & 40 \\
\hline Hotei Regio $/ 26^{\circ} \mathrm{S}, 78^{\circ} \mathrm{W}$ & T46/November 2008/CM_1604411323 & 91,200 & 45 & 520 & 67 & 14 & 81 \\
\hline Tui Regio/20ㅇ, $130^{\circ} \mathrm{W}$ & T12/March 2006/CM_1521406684 & 72,800 & 18 & 80 & 16 & 54 & 66 \\
\hline Sotra Patera $/ 15^{\circ} \mathrm{S}, 40^{\circ} \mathrm{W}$ & T09/December 2005/CM_1514309549 & 36,400 & 18 & 160 & 5 & 14 & 29 \\
\hline
\end{tabular}

${ }^{a}$ Observations including dates, flyby, and cube details such as spatial resolution, angles of incidence, emergence and phase, and exposure times of all areas investigated in this study. works, while at the same time better spatial resolution, but with higher incidence angle datacubes could not be exploited as discussed further in section 3.2.2.1. For the other areas (Tui and Sotra), we have no such problem because all the datacubes work with the RT and the preferred data represent the best available cubes in terms of spatial resolution (for the appropriate selection of Regions of Interest-or Rols) and incidence and emergence angles (for the most adequate use with our RT, see section 2.3).

\subsection{PCA Method Applied to VIMS Titan Data}

\subsubsection{The PCA Method}

The Principal Component Analysis (PCA) method is a mathematical/statistical procedure that uses an orthogonal transformation to convert a set of correlated observations into a new set of uncorrelated components, the Principal Components (PCs) [Jolliffe, 2002, 2005]. The number of PCs is less than or equal to the number of original variables. In the case of Cassini/VIMS analysis they are always equal. The new data set is sorted so that the first principal component always includes the largest possible variance. Furthermore, the PCs are guaranteed to be independent if the data set is normally distributed.

PCA has been previously applied to some planetary objects like Ganymede [Stephan et al., 2008] while for Titan, a similar algorithm that also uses principal components has been used, called the Minimum Noise Fraction (MNF), with the aim to control the dimensionality of VIMS data sets and segregate and equalize the noise in the data [Le Mouélic et al., 2012].

In this study, PCA is focused to a first-order qualitative classification of different spectral units of terrains (identified as Rols) that we complement with more qualitative RT calculations (section 3). We apply the PCA to radiometrically calibrated VIMS images of Titan. With the PCA we obtain a new coordinate system that maximizes the variance of the spectral information from the VIMS data that contain a large number of spectral channels [e.g., Richards, 1994]. Using the PCA, relevant spectral information of the VIMS data, such as the spectral properties of Titan's surface, is concentrated in fewer (PC) channels and in the best case separated from noise and the possible spectral influence of Titan's atmosphere. It has to be noted, however, that the content of the PC images strongly depends on the original information of the input data [Singh and Harrison, 1985; Gillespie, 1980]. Thus, in an analysis of VIMS data with PCA, the PC\#1 contains the "dominant" albedo features as seen by VIMS. The higher-order PCs enhance spectral differences in the VIMS data and separate them in the different PCs by frequency of appearance. We apply PCA on the 256 IR bands only, because VIMS-Visual and VIMS-IR channels do not have coincident fields of view and viewing geometry, and because on Titan, atmospheric spectral windows where the surface can be observed occur in the radiation range 1-5 $\mu \mathrm{m}$ [e.g., Jaumann, 1989; Stephan et al., 2008].

In this PCA analysis and in order to distinguish without ambiguities the PCs that correspond only or largely to the surface, we therefore select the appropriate PCs for the creation of the PCA images based on the inferred eigenvectors and eigenvalues. Thus, we are using the visual interpretation of the individual PC images, the corresponding eigenvalue, and also the corresponding eigenvectors to derive spectrally different units on Titan's surface-independently of any a priori knowledge of Titan's surface.

\subsubsection{Test Case: Sinlap Crater}

By using the PCA method we aim at creating units of color heterogeneity that each correspond to units of diverse spectral response in all of our three study areas. Le Mouélic et al. [2008] studied the Sinlap crater on Titan-one of 


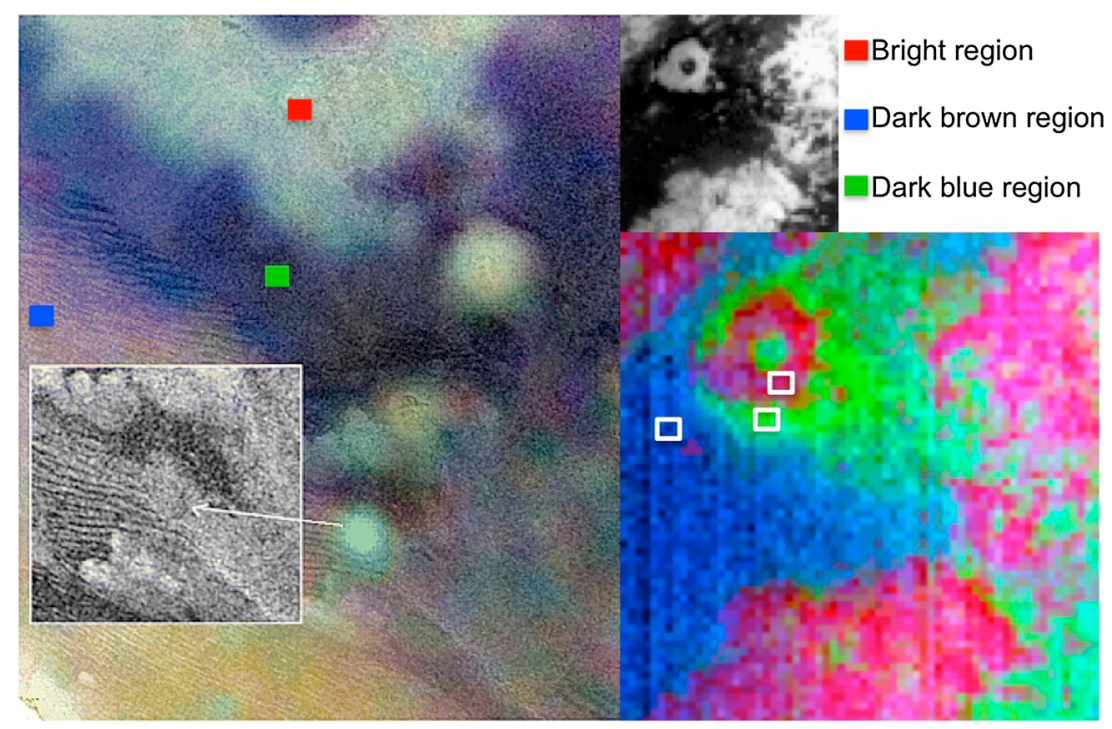

Figure 2. (left) Le Mouélic et al. [2008], on this radar/VIMS combined pan-sharpened image of the Sinlap crater region, from T3 SAR image and T13 VIMS cube CM_1525118253 taken at (top right) $2.03 \mu \mathrm{m}$, found spectral diversity between three regions. These authors used the band ratio technique in the VIMS RGB composites in this order: $R=1.59 / 1.27 \mu \mathrm{m}, G=2.03 / 1.27 \mu \mathrm{m}$, $B=1.27 / 1.08 \mu \mathrm{m}$. Such a diversity is confirmed with our PCA method which isolates (bottom right) three Rols that match the previous inferences. Following the coloring of our PCA image shown in Figure 2 (bottom right), the red rectangle in the leftsided image corresponds to a bright region, the blue to a dark brown region, and the green to a dark blue region as defined by Le Mouélic et al. [2008].

the few impact craters observed on Titan and through the use of band ratios (Figure 2) they identified several units in the VIMS false color composites that indicate compositional heterogeneities. These units correspond to specific coloring as follows: the bright ring corresponds to the ejecta blanket, the blue and dark blue area is probably enriched with water ice [Rodriguez et al., 2006] compared to the surroundings, and the brownish area corresponds to dune fields [Soderblom et al., 2007a, 2007b; Barnes et al., 2008; Rodriguez et al., 2014] (Figure 2). Such a classification led to three compositionally and geologically different types of surface regions. Applying the PCA technique in the exact same VIMS cube, we arrive at the same result of three distinct regions as seen in Figure 2 within the same regional boundaries. We thus validate our principal component application, while confirming the results by Le Mouélic et al. [2008]. We are thus certain that we select the correct VIMS pixels/ spectra (i.e., pixel selection that corresponds to a specific spectral unit) for our radiative transfer (RT) analysis.

\subsection{The Radiative Transfer Model}

The RT code used here is the one described in detail in Hirtzig et al. [2013], and the reader is referred to that paper for further explanation, more details, and additional references. This code is based on the plane-parallel version of the Spherical Harmonic Discrete Ordinate Method solver (SHDOMPP) [Evans, 2007]. It assumes plane-parallel conditions and divides Titan's atmosphere into 70 layers (from the surface up to $700 \mathrm{~km}$ ). The vertical profiles combine measurements of the pressure and temperature from Huygens/HASI [Fulchignoni et al., 2005], the methane vertical profiles from the Huygens Gas Chromatograph Mass Spectrometer (GCMS) [Niemann et al., 2010], as well as a uniform CO mole fraction equal to $4.5 \times 10^{-5}$ based on Cassini Composite Infrared Spectrometer (CIRS) measurements [de Kok et al., 2007], to reproduce the thermodynamic state and mixing ratios of the atmosphere. The opacity from methane and its isotopologues is simulated as described in de Bergh et al. [2012] and Campargue et al. [2012, and references therein], using recent developments from laboratory measurements, theoretical calculations, and empirical models. We implemented these data lists in our modular radiative transfer model, as a set of correlated-k absorption coefficients, applied here to the P, T conditions on Titan.

To reproduce a VIMS spectrum, our RT code first isolates the atmospheric contribution from the bands and deep wings of methane absorption and then retrieves the surface albedo from the methane windows of lesser absorption. Using the aerosol model (single scattering albedo and phase function) derived from Tomasko et al. [2008] and adjusted as described in Hirtzig et al. [2013], we derive the associated extinction by shifting the DISR vertical profile used as a reference, so that we fit the methane bands and windows wings 


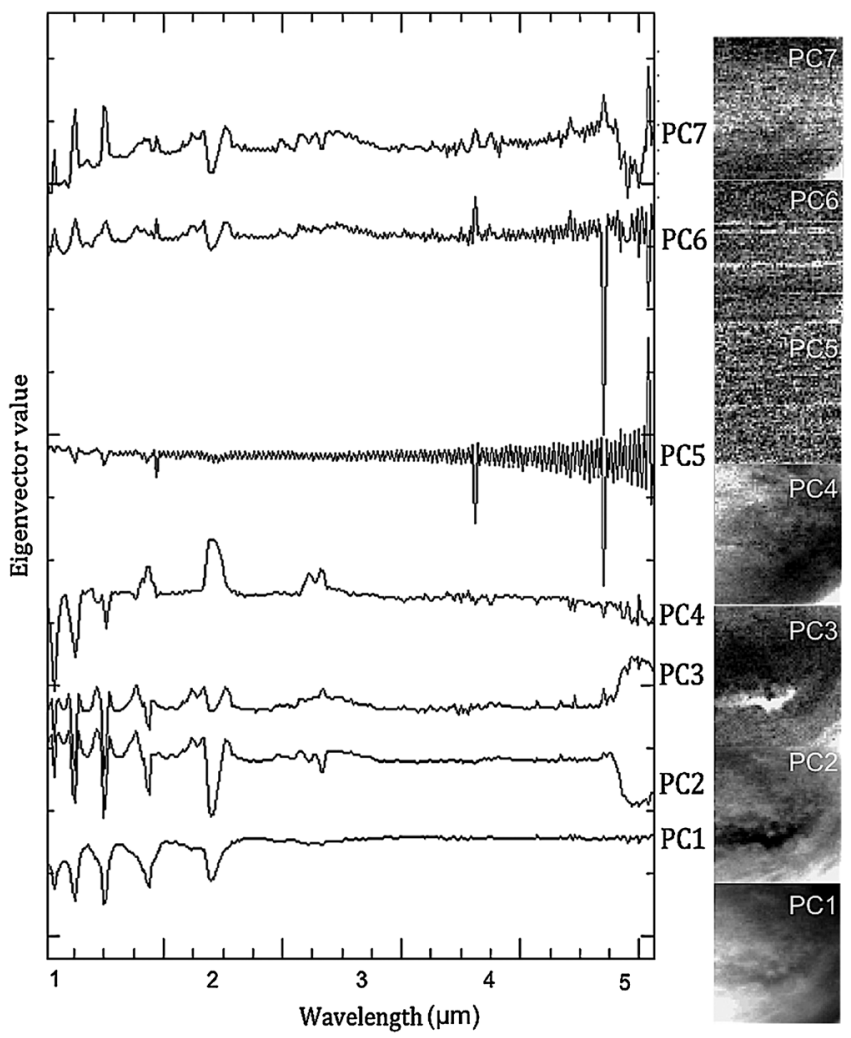

Figure 3. (left) Retrieved eigenvectors from the Tui Regio datacube (shown here as an example). (right) The seven first Tui Regio "Principal Components" (PCs). From the analysis of the eigenvectors we infer that PC1 reflects a linear combination of surface and atmosphere while PC2, PC3, and PC4 (the latter two somehow noisy) represent the surface in various proportions. The eigenvalues extracted from the PCA application suggest $\mathrm{PC} 1$ and $\mathrm{PC} 2$ as the ones with the largest possible variance throughout the IR spectrum of the datacube, while PC3 and PC4 include important information. After them, PC5, PC6, and PC7 are dominated by noise. closer to the bands centers, almost completely insensitive to surface contribution. Indeed, in the wings the surface contribution may be not nil, but the transmission of the atmosphere is so low that it blurs away the surface signal, to the notable exception of the $1.54 \mu \mathrm{m}$ region that Jacquemart et al. [2008] showed to still be sensitive to the surface in VIMS data, with a 34\% error bar as explained in detail in Hirtzig et al. [2013]. The surface albedo in most of the methane windows, on the other hand, is typically retrieved with better accuracy. As explained in Hirtzig et al. [2013] error bars on the retrieved albedos are due to random errors due to noise in the data and to the propagation of haze retrieval errors, as well as systematic errors due to model. When considering albedo differences between two regions the random errors were combined quadratically. In contrast, at 2.0, 2.7, and $5 \mu \mathrm{m}$ systematic uncertainties dominate the error budget. So that in the end, our results are retrieved with an accuracy around $15 \%$, at $1.28,1.59$, and $2.0 \mu \mathrm{m}$ taking into account the uncertainties on the far-wing profiles and the $\mathrm{CH}_{4}$ linelists, the haze extinction fit and the vertical concentration, as well as the calibration and the data intrinsic noise.

The error bars at 0.94 and $1.08 \mu \mathrm{m}$ (where we do not have new $\mathrm{CH}_{4}$ spectroscopic data) as well as at the noisier $5.0 \mu \mathrm{m}$ window are thus estimated to be $33 \%$. For the double $2.69-2.79 \mu \mathrm{m}$ window, they are higher and can reach $40 \%$. With these uncertainties in mind, we thus display computations in the $0.94,1.08,1.28$, $1.59,2.03,2.69-2.79$, and $5.0 \mu \mathrm{m}$ methane windows and an additional value for the $1.54 \mu \mathrm{m}$ wing.

We note that depending on the geometry the signal of the atmosphere could produce a higher I/F spectrum for a darker (in terms of albedo) area. For instance, a large airmass observation shows a higher I/F spectrum which does not necessarily translate into a high surface albedo. Furthermore, depending on the $\mathrm{CH}_{4}$ opacity parameters, a higher I/F in a given window does not necessarily mean a higher surface albedo with respect to the other windows, it could be lower. All of this is taken into account in our simulations.

Our primary goal, at the end of our analysis, is to compare the surface features of Hotei, Tui, and Sotra that are already defined by previous studies as mentioned earlier, with the surrounding areas and among themselves trying to detect relative spectral variations associated to diversity in the surface composition and to see if and how they could be connected to morphology.

\section{Results}

\subsection{PCA Results on Study Areas}

We apply the PCA method to the three study areas: Hotei Regio, Tui Regio, and Sotra Patera. Figure 3 shows the eigenvectors as retrieved from the Tui Regio datacube and a series of the seven first PCS of the VIMS 


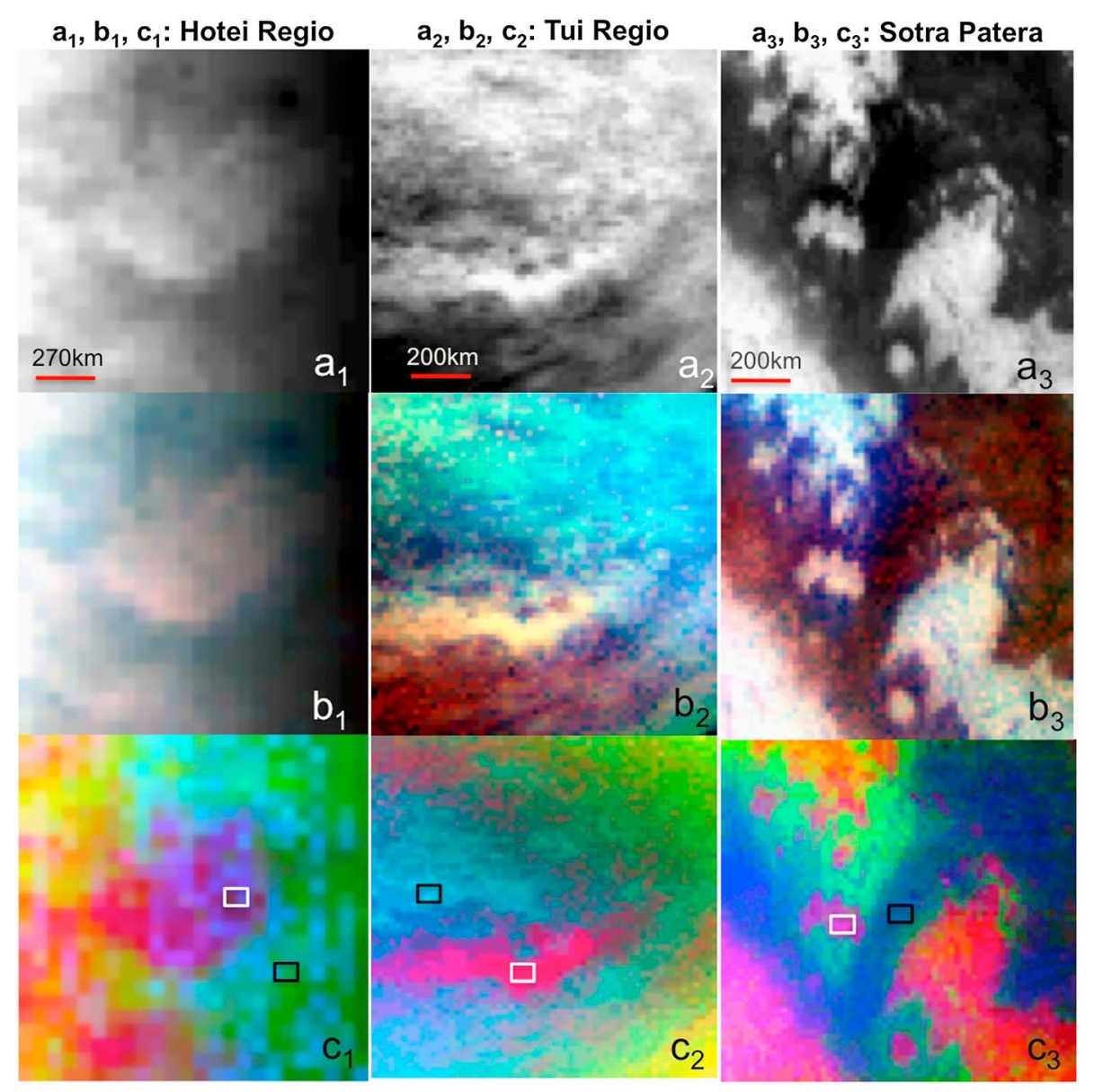

Figure 4. VIMS images for $\left(a_{1}-c_{1}\right)$ Hotei Regio, $\left(a_{2}-c_{2}\right)$ Tui Regio, and $\left(a_{3}-c_{3}\right)$ Sotra Patera showing the spectral diversities of these areas. Figures $4 a_{1}-4 a_{3}$ shows the $2.03 \mu \mathrm{m}$ band. Figures $4 b_{1}-4 b_{3}$ shows the RGB composite of the same spectroimages (with $R: 5.0 \mu \mathrm{m}, G: 2.03 \mu \mathrm{m}, B: 1.08 \mu \mathrm{m}$ ). Figures $4 c_{1}-4 c_{3}$ shows the RGB composition of the PCs showing most of the surface contribution separated into three spectral units: one red, one green, and one blue. The white boxes include the pixel selections from the Hotei, Tui, and Sotra Rol areas, and the black ones represent the chosen surrounding Rols.

observation of the area, where the first four, as showed by the eigenvalues, retain most of the data variability present in all of the original variables.

The analysis of the eigenvectors shows that PC1 reflects the atmosphere in addition to some surface features while $\mathrm{PC2}, \mathrm{PC}$, and $\mathrm{PC} 4$ (the latter two containing a little more noise) reflect the surface spectral contributions (Figure 3). After that, PC5, PC6, and PC7 are dominated by noise. Thus, for Tui Regio, we will hereafter use RGB composites of the three main principal components related only to the surface. As an example, we show on Figure 4 Tui Regio, where the main principal components are \#s 2, 3 , and 4 (Figure $4 \mathrm{c}_{2}$ ).

PCA is not sensitive to brightness; thus, we chose to use a certain color identification so that the spectral units that correspond to the features inside Hotei, Tui, and Sotra appear in red and the surrounding units in green or blue and applied this color coding to the PCA outputs of all datacubes. With such a representation, it is possible to identify a number of Rols that qualitatively indicate the most diverse spectral response and possibly different chemical compositions (Figure 4). We select two small Rols as close as possible to each other in the area, so that we can safely assume that the atmospheric contribution and the observational geometry is similar ensuring that any changes in reflectivity are mainly due to the surface (Figures $4 c_{1}-4 c_{3}$ ). In Hirtzig et al. [2013] the "Bright Tui" region has been selected from a different VIMS cube (Tb from 2004) with higher spatial resolution but showing only the eastern part of Tui, which nevertheless agrees with our PCA Rol result for the brightest region. 

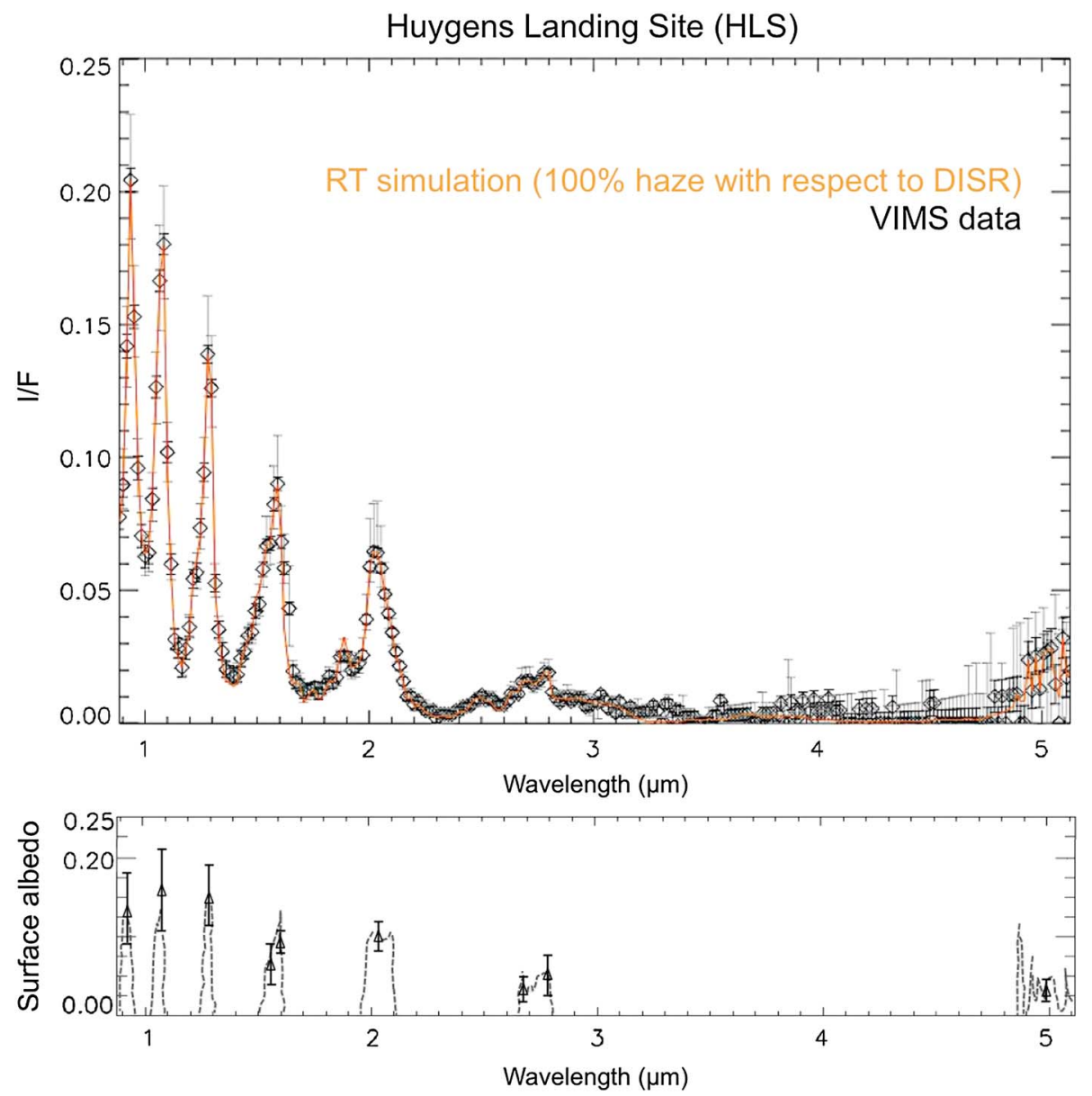

Figure 5. (top) Huygens Landing Site. (bottom) Surface albedo. Figure 5 shows the best fit of the spectrum of the Huygens Landing Site (HLS) showing all the methane windows (VIMS HLS data in black and the RT simulation in orange) from which we retrieved the full resolution surface albedo spectrum in the $0.89-5.1 \mu \mathrm{m}$ range as shown in Figure 5 (bottom) and the points plotted in the center of the methane windows which represent the weighted average of the surface albedo within the window, with larger weights for channels with high transmittance around the center. Note that the albedo plotted at $1.54 \mu \mathrm{m}$ corresponds to the result for a spectral region centered in the wing of the methane band, which is still somewhat sensitive to the surface albeit subject to higher uncertainty (this also applies to Figures 6-9).

An additional advantage of PCA, other than identifying and applying the observing conditions (Figures 3 and 4), is the ability to distinguish any clouds present in the data, which would appear in a separate Rol, distinct from the surface features, due to their very specific spectral signatures [Rodriguez et al., 2009, 2011]. In the three study areas, we did not find any cloud Rol, as also confirmed by independent VIMS observations.

\subsection{Radiative Transfer (RT) Modeling Results}

With PCA we have isolated two distinct regions within the three study areas, one from within the area itself (red) and one from the surrounding terrain (green/blue) (Figures $4 c_{1}-4 c_{3}$ ), on which we apply the radiative transfer model and present the results in this section.

\subsubsection{The Huygens Landing Site}

We first use the RT code to simulate the spectra and retrieve the surface albedo of the Huygens Landing site (HLS) (Figure 5), which is used for validation and comparison purposes. The RT code gives the best fit of the observations shown in Figure 5 (top), while in Figure 5 (bottom), we plot the results for the surface albedo in two different forms: (a) the full resolution surface albedo spectrum in the $0.89-5.1 \mu \mathrm{m}$ range and (b) points plotted in the center of the methane windows representing in fact the weighted average of the surface albedo in and around the window center, with larger weights applied to the channels with high 
transmittance (and thus higher confidence), and lower weights on optically thick channels [Hirtzig et al., 2013]. The HLS observations are very useful as they provides the only "ground truth" for Titan's surface from Huygens. The haze extinction profile reference is adopted to be the one from the DISR results; thus, for HLS the adjustment factor is $100 \%$. The HLS albedo retrieval with our RT code (Figure 5) shows a trend indicating a decrease in surface albedo from shorter to longer wavelengths. This is compatible with what is found in Hirtzig et al. [2013] for the DISR spectral range (the reader is referred to that paper for further information and their Figure 10), where it is shown that shorter than $1.6 \mu \mathrm{m}$ the retrieved surface albedos agree with those derived from Huygens/DISR [Jacquemart et al., 2008], and our results also agree with those extended to longer wavelengths of Griffith et al. [2012].

\subsubsection{Surface Albedos From the Studied Areas}

We then process the Rols of the three other study areas with our RT and retrieve the surface albedos for both the "area" and the "surrounding" Rols. As mentioned previously, our RT code allows us to retrieve not only the surface albedo but also an estimate of the total aerosol content, compared to the reference measurement by DISR (Figure 5). We note that in the case of the double window at 2.69 and $2.79 \mu \mathrm{m}$ [Coustenis et al., 2003], the absolute surface albedos, although nominally different in all areas, are always compatible within error bars, with, however, generally a higher albedo for the longer wavelength of the two.

In the figures showing our results for surface albedos we present nine points. Eight of these are for the methane window centers, whereas the albedo plotted at $1.54 \mu \mathrm{m}$ corresponds to the result for a spectral region average centered in the wing of the methane band but still somewhat sensitive to the surface (albeit subject to higher uncertainty).

\subsubsection{Hotei Regio}

We first applied this processing to Hotei Regio data. As explained in section 2, the corresponding fits (shown in Figure 6 (top)) suffer from large uncertainties due to the fact that the observing geometry of the Hotei data reaches the limit of compatibility with our plane-parallel code (close to both the limb and the terminator, therefore with an incidence angle greater than $60^{\circ}$ ) and lower spatial resolution than the other regions. Indeed, the code failed to work for some of the Hotei Regio datacubes processed with RT due to their extreme geometries but produced a correct result for others.

We therefore here use a cube for Hotei Regio that we have found to have the best possible combination of observing conditions up to 2013 (Table 1, Hotei Regio, November 2008, resolution $45 \mathrm{~km} /$ pixel, incidence $67^{\circ}$, emergence $14^{\circ}$ ). We obtain the best fits of the two Rols in this cube from the RT model and then retrieve the surface albedos, as shown in Figure 7. In this figure, where we look at differences between the different Rols and for clarity purposes we only plot the surface albedo points that are weighted averages (see section 3.2.1). The haze extinction profile reference in this case needs to be adjusted by a factor of 0.83 for the Hotei Regio Rol and 0.78 for the surrounding Hotei Rol, therefore indicating very similar haze content above both areas.

With all these caveats in mind, the results from our preferred datacube (Figure 7) show that the surface albedo of the Hotei Rol and its surrounding area are rather similar in shape with a maximum at $1.28 \mu \mathrm{m}$ and a minimum at $5.0 \mu \mathrm{m}$, but the Hotei Regio Rol's albedo per se is higher than the surrounding one, especially at longer wavelengths, by a factor of 2 at $2.03 \mu \mathrm{m}$ and up to a factor of 3 at both $2.69-2.79 \mu \mathrm{m}$ and $5.0 \mu \mathrm{m}$ (Figure 6). Thus, Hotei's surface is brighter in the near-IR than the surrounding area, as also reported by Nelson et al. [2009a] from the analysis of other earlier Hotei Regio datacubes, but also exhibits a different dynamical range. The shape of the surface albedo spectrum from Hotei Regio indicates higher albedos (0.33-0.51) at short wavelengths, especially at $1.28 \mu \mathrm{m}$ and $\sim 2-3$ times lower ones from 2.6 to $5.0 \mu \mathrm{m}$ (Figure 7).

\subsubsection{Tui Regio}

Our best fits of the spectra of Tui Regio and its surrounding Rols (selected through our PCA, see Figure 4) are shown in Figure 6 (middle). The RT code indicates that the aerosol population of Tui Regio Rol is 0.70 times the HLS one and 0.75 for the surrounding Tui Rol and therefore quite similar with each other with $10 \%$ variation within Hotei. The aerosol population in the code is the DISR-derived haze extinction vertical profile $k(z)$ (above the Huygens landing site) multiplied by a multiplying factor $f$. We can derive from that the $f . k(z)$ number the total haze opacity tau(lambda). Figure 7 shows the absolute surface albedos we retrieved in blue for the Tui Rol and in cyan for the surrounding Rol. The differences in surface brightness between the two regions are large, especially at the longer wavelengths, as for Hotei, but also in the shape. More in detail, there is a monotonic increase in difference of surface albedo with wavelength, particularly at $2.03 \mu \mathrm{m}, 2.69-2.79 \mu \mathrm{m}$, and $5.0 \mu \mathrm{m}$, where Tui is 

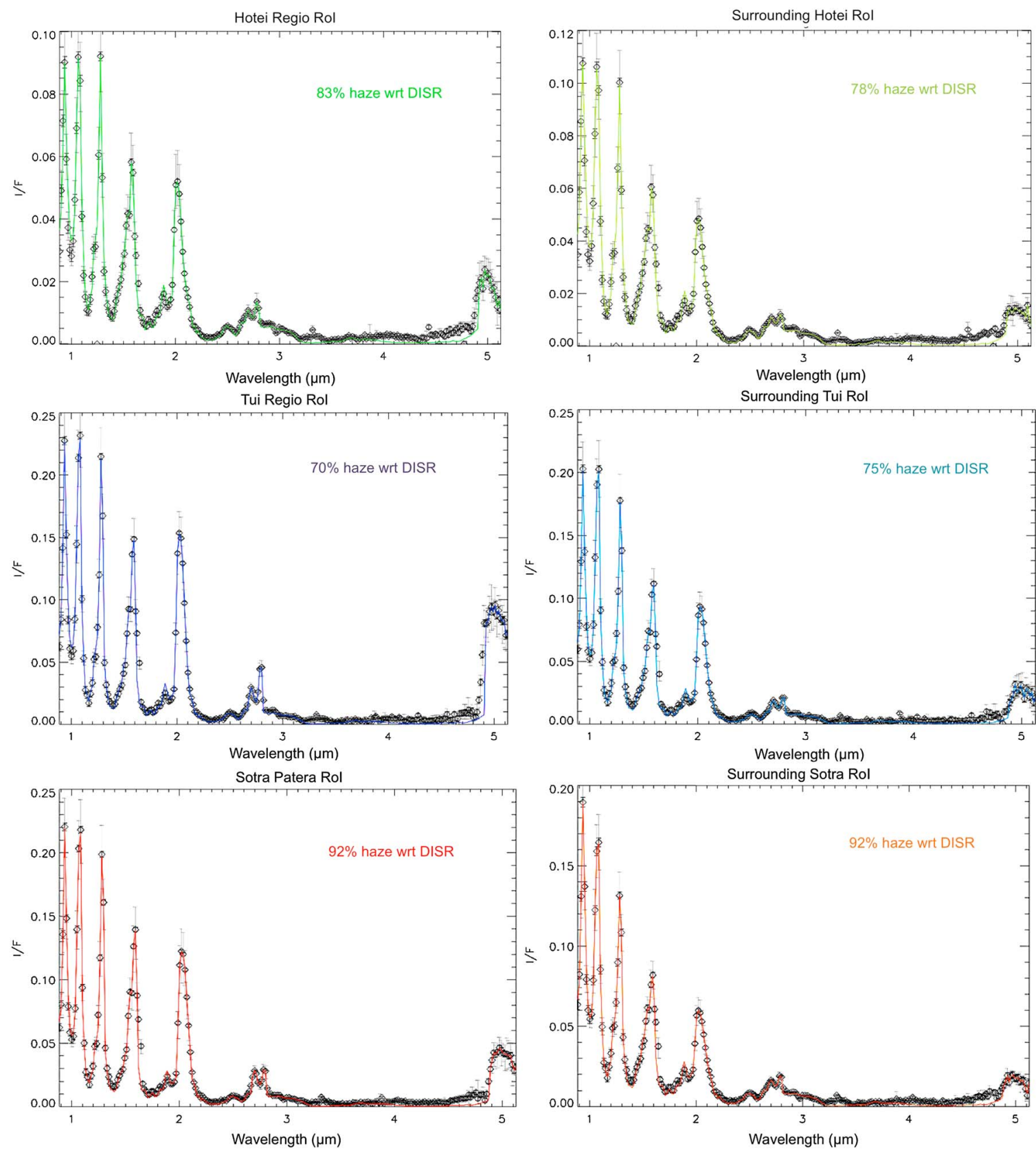

Figure 6. (top) Best RT fits of the spectra for Hotei Regio (green) and the surrounding Rol (light green), (middle) in blue for the Tui Regio Rol and in cyan for the surrounding Tui Rol as indicated by PCA (see Figure 4) and for the (bottom) Sotra Patera Rol in red and the surrounding Sotra Rol in orange.

brighter than the surrounding regions by factors of about 2,3, and 4, respectively, with larger uncertainties for the latter two wavelengths. Similarly to Hotei but with different nominal values, the Tui Regio Rol spectrum shows a plateau around $0.25-0.3$ for the surface albedo at $1-2 \mu \mathrm{m}$, then a sharp drop at $2.69 \mu \mathrm{m}$ (at 0.1 ), followed by a rise to another plateau around 0.2 from 2.79 to $5 \mu \mathrm{m}$. The $2 \mu \mathrm{m}$ value for Tui Regio appears high, the maximum in its surface spectrum, while in all other areas, the maximum is usually to be found in the 1-1.3 $\mu \mathrm{m}$ region. Figure 8 also shows that the minimal values of the Tui spectrum are found around $0.94,2.69-2.79$, and $5 \mu \mathrm{m}$, but the $5 \mu \mathrm{m}$ value is not the lowest one, contrary to the surrounding region, which exhibits three "floors" after $1 \mu \mathrm{m}, 1-1.3,1.6-2$, and $2.6-5 \mu \mathrm{m}$ in descending albedo order. If we believe the nominal surface albedo values, Tui's surface is then brighter at the longer wavelengths that the two other areas and the surrounding ones, especially at $5.0 \mu \mathrm{m}$ (as reported also in previous studies). 


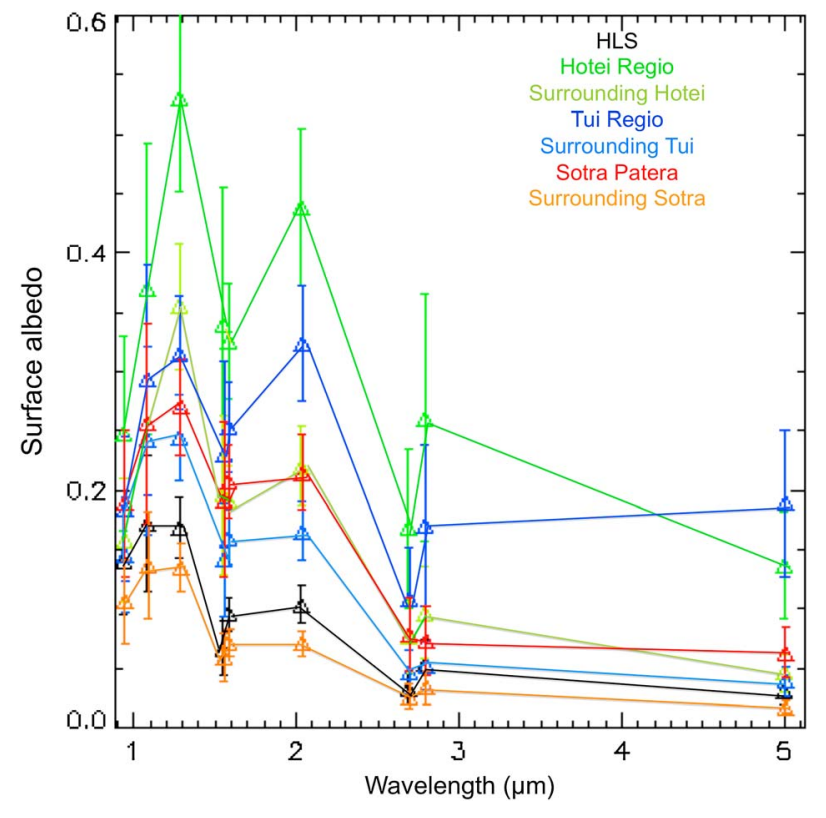

Figure 7. Weighted averages in the methane windows of the surface albedos of Hotei Regio (green), Tui Regio (blue), and Sotra Patera (red) and their surrounding Rols (light green for Hotei, cyan for Tui, and orange for Sotra). In black is the HLS surface albedo for comparison purposes.

\subsubsection{Sotra Patera}

The PCA method returns a distinctly different set of eigenvectors than the ones from Tui Regio. For this region, which is almost $235 \mathrm{~km}$ in diameter, far more reduced in size than Tui Regio $(1500 \times 150 \mathrm{~km})$ and Hotei Regio $(700 \times 700 \mathrm{~km}), \mathrm{PCA}$ is able to differentiate two behaviors within each of the Sotra Patera and the surrounding regions. The spectral units with high I/F values appear either red or yellow, while the other fields (low I/F) of Fensal (sand sea with dark albedo centered at $50^{\circ} \mathrm{N}, 30^{\circ} \mathrm{W}$ ) are split into green or blue regions, most certainly related to the fields of dunes (green) and the water ice remnants (blue), known as "dark brown" and "dark blue" regions, respectively [Rodriguez et al., 2006, 2014; Soderblom et al., 2007b] (see Figure $4 c_{3}$ ). Figure 6 (bottom) shows the best RT fits of spectra for the Sotra Patera Rol spectra (in red in the plot) and the surrounding

Sotra Rol (in orange in the plot). The RT code indicates that the aerosol population for the Sotra Patera and the surrounding Sotra Rols is 0.92 times the HLS one, somewhat higher than for Tui and Hotei Regio, where the factor of adjustment was closer to $0.7-0.8$. Given the different dates we are considering here for each area (2-3 years gap) this can be due to slight seasonal changes in the total aerosol content of the atmosphere. From Figure 7 we see that the absolute surface albedo retrieved for the Sotra Patera Rol is higher than the surrounding Sotra Rol's by a rather constant factor of 2-3 depending on the wavelength, with the largest differences again around $5.0 \mu \mathrm{m}$. This is different from the other regions where at the shorter wavelengths the study regions are always within a factor of $30-60 \%$ of the surrounding terrains, and thus, Sotra appears more similar in shape to the area around, albeit considerably brighter. The Sotra lowest surface albedo values are at around 0.07 from 2.6 to $5 \mu \mathrm{m}$, while the short-wavelength plateau is here 3.5 times higher, presenting the strongest excursion within the spectrum. We also note that Sotra has almost the same albedo in the 2.6-2.8 $\mu \mathrm{m}$ region, a characteristic common in the surrounding areas, in general, but not in Hotei or Tui if we look at the nominal values.

\subsubsection{Comparison Between Hotei and Tui Regio and Sotra Patera}

From Figure 7 we see that the surface albedo spectra of the three regions in study here present some similarities but also marked differences, so that they cannot be considered to be of the same composition, not among them nor when compared to the surrounding regions. We note that the Rols we selected from the surrounding areas are, in general, darker than the study areas of Hotei, Tui, and Sotra and also close to the surface albedos found for the HLS. Figure 8 shows the ratios of averaged values of the surface albedos of the different Rols.

We first compare the surface albedo of Tui Regio and Sotra Patera retrieved from data acquired within a period of 3 months (for Tui Regio March 2006, for Sotra Patera December 2005), thus close in time. The results are shown in Figure 8 (top). We find that Tui Regio's surface is always brighter than Sotra Patera's (we note that the haze content, while more important above Sotra Patera, is still within $15 \%$ of each other). The brightness difference of the Tui Regio Rol with respect to Sotra's increases constantly with wavelength (Figure 8) with factors up to 2 at $2.79 \mu \mathrm{m}$ and 3 at $5.0 \mu \mathrm{m}$. This is probably indicative of weaker absorption by water ice for such $5 \mu \mathrm{m}$ bright regions. The surrounding Sotra Rol is spectrally similar to Tui's but darker by factors of $1.5-2.5$ almost everywhere. While the overall difference in brightness could be due to morphological and/or textural variations, the distinct spectral behavior (notably at 2, 2.79, and $5 \mu \mathrm{m}$ ) is probably a good indicator of differences in the composition of each region. 

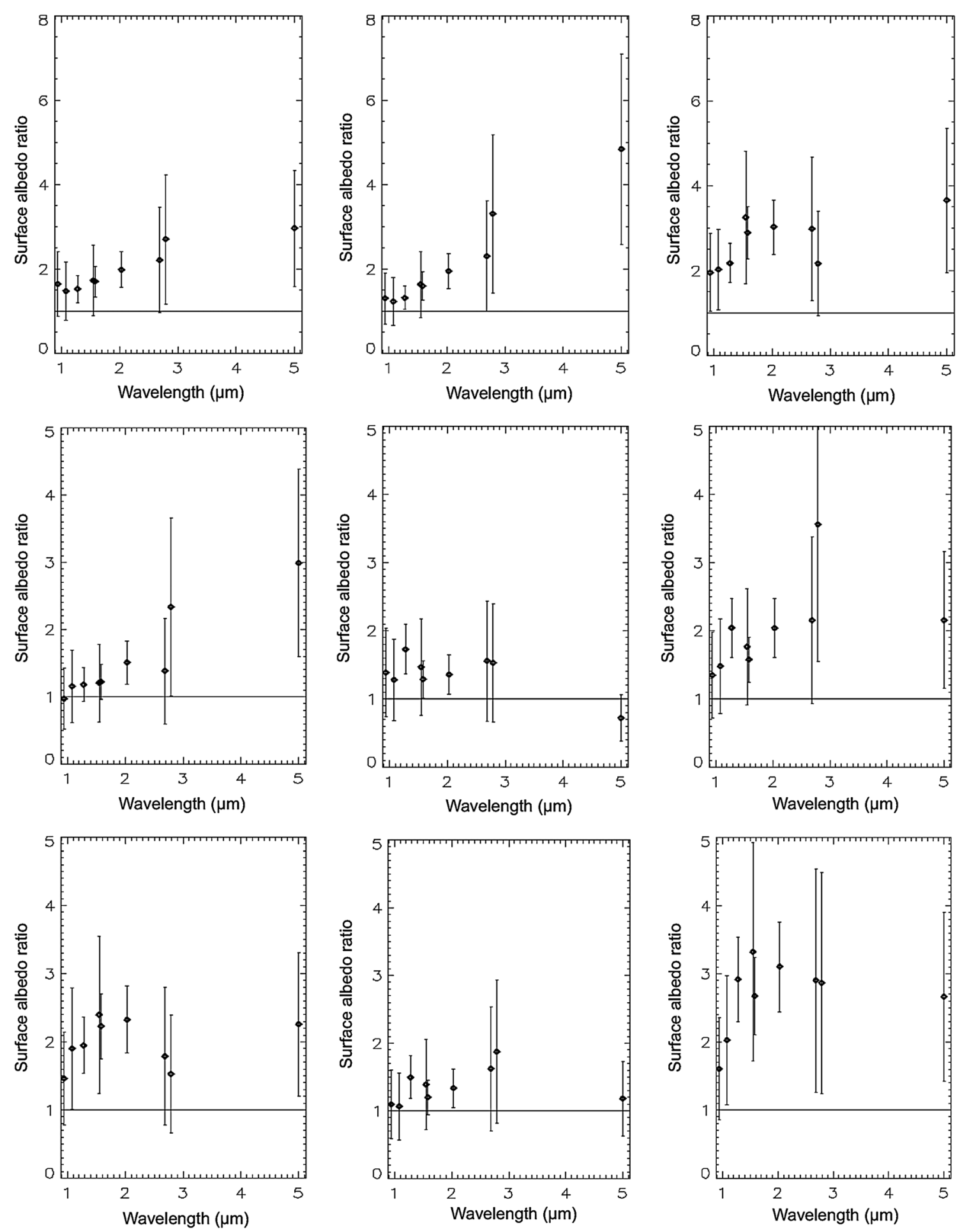

Figure 8. (top: left to right) Surface albedo ratios (from the weighted averaged points) of the Hotei Regio, Tui Regio, and Sotra Patera Rols with respect to their surrounding darker Rols. (middle panel: left to right) Tui Regio Rol with respect to Sotra Patera, Hotei Regio with respect to Tui Regio, and Hotei Regio with respect to Sotra Patera. (bottom) Same as Figure 8 (middle) but for the surrounding Rols.

The comparison between the areas of Hotei Regio and Tui Regio (Figure 8, middle) shows that they are spectrally very similar, although Hotei is always brighter than Tui by about $40-50 \%$, except at $1.28 \mu \mathrm{m}$ where the increase in albedo reaches $70 \%$ and at $5.0 \mu \mathrm{m}$ where in a reversed situation, Hotei can be up to $30 \%$ darker than Tui (Figure 8). In addition, while for Hotei the difference in albedo from short to long wavelengths 
can reach factors of 3, for Tui the difference is only half that. Therefore, for all these reasons Tui's surface spectral behavior is different from Hotei's, especially at 1.28 and $5 \mu \mathrm{m}$. The ratio of the surface albedo of the surrounding Rols shows that Hotei's surrounding is also brighter that the Tui one with the most significant difference at $2.79 \mu \mathrm{m}$, which is almost $90 \%$. No difference is observed at $5 \mu \mathrm{m}$ for the surrounding areas.

In addition, Figure 8 (bottom) shows the ratio of Sotra Patera Rol with respect to Hotei Regio's. Hotei is brighter than Sotra at all wavelengths by a mean factor of more than 2 for 1.28, 2.03, 2.69, and $5 \mu \mathrm{m}$, and up to 3.5 at $2.79 \mu \mathrm{m}$. The surrounding Rol of Hotei is also constantly brighter than Sotra's at all wavelengths similarly to Tui's case, by factors of 2-3.5.

\section{Interpretations and Conclusions}

We have applied a statistical method and a radiative transfer code on VIMS data in order to retrieve the effective surface contribution separated from the associated atmospheric content in the spectra of four Titan areas, including the HLS (used for validation and comparison purposes). For these regions, of different spectral behavior, we then extracted the absolute surface albedos, which enabled us to evaluate the dynamical range and differences between them. We have found that the Hotei Regio processing presented difficulties due to the unfavorable acquisition conditions of the observations. Thus, even though the datacube in use here was selected very carefully and the code worked, the results should be treated with caution due to the high values of the incidence angle of the observation and the use of our plane-parallel radiative transfer code.

For all study areas, the surface albedos showed that the Rols of the spectral units of Hotei, Tui, and Sotra are brighter at all near-IR wavelengths than the corresponding surrounding Rols, in agreement with what Barnes et al. [2005, 2006] found for Hotei and Tui. The lower albedo of the surrounding Rols coincides rather closely with the HLS surface albedo, within a factor of 1.5 or so, especially at longer wavelengths. This confirms previous results indicating that HLS is mostly a rather dark region [Rodriguez et al., 2006] and that the surrounding areas are also rather dark.

Comparing the retrieved surface albedos from Hotei Regio, Tui Regio, and Sotra Patera we find that their shapes present some similarities, but they differ in brightness and in the dynamic range between the two plateaus at short and longer wavelengths (Figure 8 and previous section). In addition, Tui is always brighter than Sotra, with the largest surface albedo difference at 2.79 and $5 \mu \mathrm{m}$, up to a factor of 3 . The same applies to Hotei Regio, which is always brighter than Sotra up to a factor of 4 at $2.79 \mu \mathrm{m}$. Furthermore, Hotei's surface is brighter than Tui's up to a factor of 2 at all wavelengths except the $5 \mu \mathrm{m}$ one where Hotei is dimmer by about $30 \%$ with respect to Tui.

Furthermore, the surface albedos inferred here for all main studied areas (Figure 7) display their largest variations with respect to the surrounding regions longward of $2 \mu \mathrm{m}$ and mainly at 3-5 $\mu \mathrm{m}$, with higher albedos in the Rols themselves by factors of 3 (for Sotra Patera and Hotei Regio) and up to a factor of 5 (for Tui Regio). Tui and Hotei seem to be anomalously bright at $5 \mu \mathrm{m}$, again in agreement with previous studies [Barnes et al., 2005, 2006, 2007b; McCord et al., 2006, 2008; Soderblom et al., 2009]. The fact that the difference in albedo is not homogeneous across the spectrum argues against its origin being only due to relief or any other simple morphological or grain size considerations. Rather, some compositional variations are in play, and such chemical diversity indicates, in general, that different endogenic and/or exogenic processes have shaped these regions. The chemical identification of the material presents an intriguing as well as a difficult problem.

\subsection{Surface Composition Constraints}

As said in the previous subsection, when we compare the Tui Regio Rol with its surrounding one, we find significant differences, with an importantly higher surface albedo for the Tui Rol, especially at the longer wavelengths, mainly at 2.69, $2.79 \mu \mathrm{m}$ and $5 \mu \mathrm{m}$, similarly to Hotei. This could mean that Tui's and Hotei's regions contain a surface component, which is significantly brighter at 2.69-2.79 and $5 \mu \mathrm{m}$, in agreement with some of the results by Barnes et al. [2006]. Conversely, it could mean that the regions that are bright at $5 \mu \mathrm{m}$ are poor in a constituent with strong absorption bands in these ranges of wavelengths, such as, for instance, water ice.

The Sotra Patera Rol spectrum presents increased values of surface albedo at all wavelengths with respect to the surrounding Sotra Rol spectrum, especially after $1.6 \mu \mathrm{m}$, where a plateau with factors of increase of 3-4 is 
reached. This indicates that any differences in composition of the surface in this area again concern mainly the longer wavelengths, but from 1.6 and beyond, rather than only at 3-5 $\mu \mathrm{m}$ as for Tui and Hotei Regio.

As done in previous studies [Negrão et al., 2006; McCord et al., 2008; Le Corre et al., 2009; Hirtzig et al., 2013], we compare here our derived surface albedos with available spectra for several ices, tholin, and other material, which could be present on Titan to attempt an interpretation of the surface albedo behavior. This was done, for example, for Tui Regio in the recent study by Hirtzig et al. [2013] in which the authors compare with different grain sizes water ice, bitumen, and tholin material. In this paper, and without entering in too much detail on possible compositional mixtures, we show in Figure 9 a comparison of our surface albedo for Hotei Regio, Tui Regio, and Sotra Patera in full resolution with a set of most likely (or "more often proposed") candidates for Titan's terrain: $\mathrm{H}_{2} \mathrm{O}$ (with a grain size dependence), $\mathrm{CO}_{2}, \mathrm{NH}_{3}, \mathrm{CH}_{4}$ ices, bitumen, and tholin, as was done in previous studies (e.g., in recent works by Negrão et al. [2006], Rodriguez et al. [2006], McCord et al. [2008], Griffith et al. [2012], and Hirtzig et al. [2013]). The albedo spectrum of each material was calculated from Spectrimag [Douté and Schmitt, 1998], using the Khare et al. [1984] optical constants for tholins as a basis. The material data come from various sources as follows: Schmitt et al. [1998] and Grundy and Schmitt [1998] for water ice, $\mathrm{CO}_{2}$ [Quirico and Schmitt, 1997; Quirico et al., 1999], $\mathrm{NH}_{3}$ [Schmitt et al., 1998], $\mathrm{CH}_{4}$ [Grundy et al., 2002], bitumen suggested by Lellouch [2006], and different kinds of tholins [Coll et al., 1999; Bernard et al., 2006]. For the variations with grain size and also for some mixtures of these constituents we refer the reader to these publications.

Our results indicate that most of the surface albedos of the Rols in the three areas are compatible with water ice because of the high values at the short (1-1.3 $\mu \mathrm{m}$ ) wavelengths and the low values near 3 and $5 \mu \mathrm{m}$. However, in the regions that appear bright at the longer wavelengths, water ice must be in smaller amounts to account for the weaker absorptions, unless a bright component is present. It also appears that the $\mathrm{H}_{2} \mathrm{O}$ grain size should be rather small (e.g., 25-60 $\mu \mathrm{m}$ ) than big (e.g., 750-1000 $\mu \mathrm{m}$ ) to account for the lower absorptions than expected at 1.6, 2, 3, and $5 \mu \mathrm{m}$. In particular, our results indicate quite elevated albedo values at $2 \mu \mathrm{m}$. Some other material is also required to be mixed with the ice in order to explain the lower values at 0.94 and $1.08 \mu \mathrm{m}$, and the tholin spectrum is compatible with such a behavior (as previously also reported by, e.g., Coustenis et al. [1995], Griffith et al. [2003, 2012], Lellouch et al. [2004], Tomasko et al. [2005], Negrão et al. [2006], Rodriguez et al. [2006], McCord et al. [2008], and Le Mouélic et al. [2008]). Bitumen has also been suggested as capable of lowering the total surface albedo in some areas, such as, for instance, in the surrounding darker terrains.

However, the total spectral behavior we derive here, and as pointed out in the Hirtzig et al. [2013] study, does not seem to be completely satisfied with any combination of just these components. Among other possible ices, we note that the high $2 \mu \mathrm{m}$ values that we infer do not work with $\mathrm{NH}_{3}$ which shows a strong absorption at these wavelengths and can then be excluded especially added to $\mathrm{H}_{2} \mathrm{O}$, which should yield even lower values in that region. The rather large $2 \mu \mathrm{m}$ surface albedos could perhaps be compatible with $\mathrm{CH}_{4}$ ice, which has no absorption at $2 \mu \mathrm{m}$ and also with $\mathrm{CO}_{2}$ ice, which has a weaker absorption at $2 \mu \mathrm{m}$ and whose signature could also accentuate the drop at $2.7 \mu \mathrm{m}$. We therefore agree with previous publications, which suggest $\mathrm{H}_{2} \mathrm{O}$, $\mathrm{CO}_{2}$, and $\mathrm{CH}_{4}$ ices, as well as tholin material as possible constituents on Titan's surface [Coustenis et al., 1995; Griffith et al., 2003; Negrão et al., 2006; McCord et al., 2008]. We also note that the $2 \mu \mathrm{m}$ rise and the $2.7 \mu \mathrm{m}$ drop is more pronounced in the case of Hotei and Tui Regio than for Sotra, where the surface albedos are at the same level in the 1-2 $\mu \mathrm{m}$ range, and 2-3 factors lower at longer wavelengths.

Further investigation to identify the material or the materials that cover the candidate areas is required, while it is clear that even within a given area there are different Rols that may have distinct compositions.

We are indeed far from the global spectral homogeneity of the surface one would expect given the settling of atmospheric aerosols over geological timescales on Titan. More and more localized heterogeneities are reported, as in the areas studied here. Indeed, as Hirtzig et al. [2013] pointed out, contrary to other areas, Tui Regio shows a large excess of small-sized tholins over the water ice content, with no specific spectral signature. Such localized surface differences with respect to the surrounding areas are possibly due to the presence of secondary material and/or the result of recent (regarding the rate of rehomogenization by aerosol settling) material depositions and redistribution in surface composition [e.g., Soderblom et al., 2009]. 

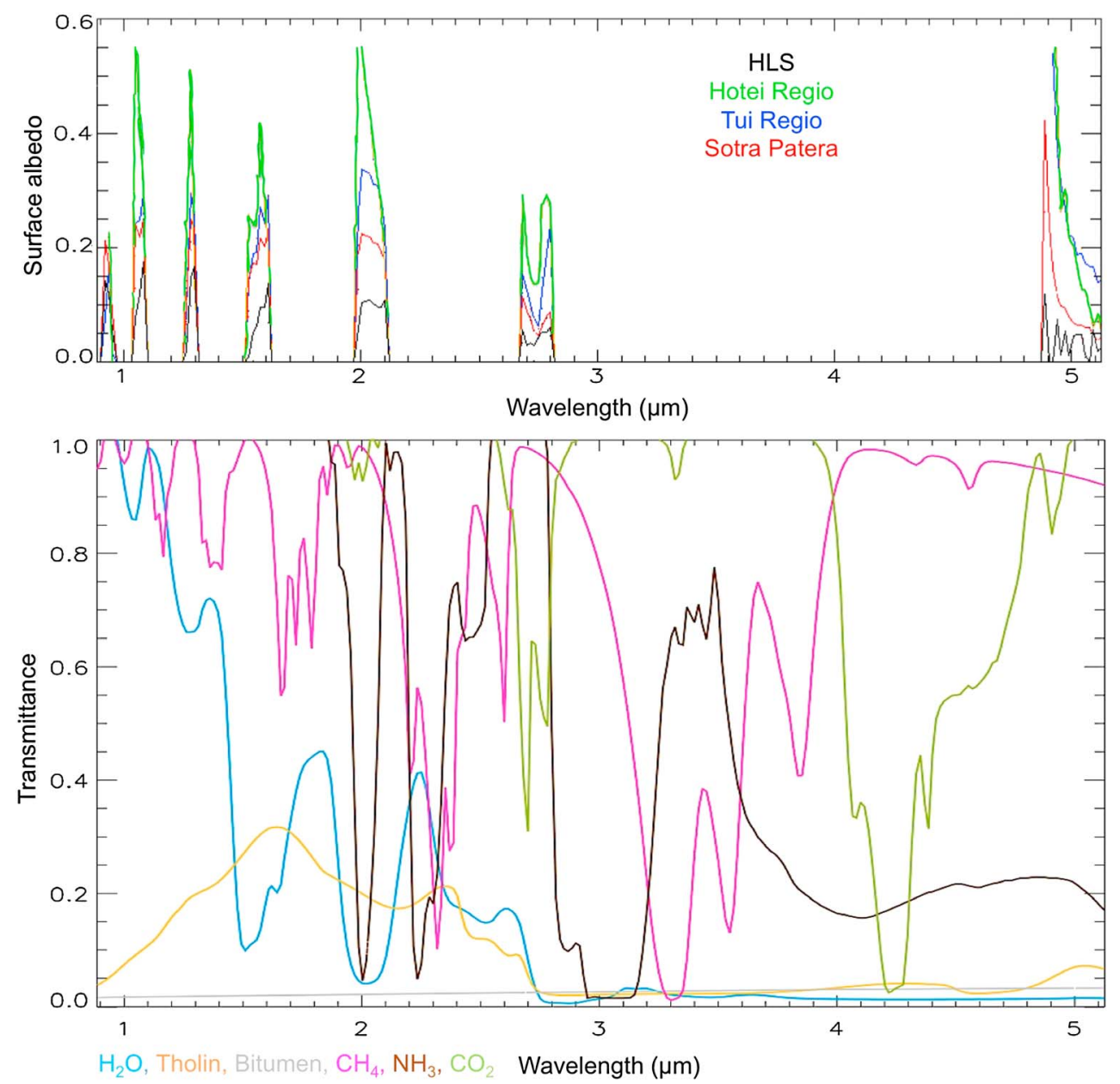

Figure 9. (top) Surface albedos retrieved from RT simulations of the VIMS spectra (at a full resolution of about $13 \mathrm{~nm}$ below $2.0 \mu \mathrm{m}$ that increases up to $22 \mathrm{~nm}$ at $4.2 \mu \mathrm{m}$ and decreases to $18 \mathrm{~nm}$ at $4.8 \mu \mathrm{m}$ ) for the Huygens Landing site (black), Hotei Regio (green), Tui Regio (blue), and Sotra Patera (red); (bottom) transmittance spectra of some possible pure chemical candidates of Titan's surface $\left(\mathrm{H}_{2} \mathrm{O}\right.$ ice with $300 \mu \mathrm{m}$ grains size in light blue; tholin $(100 \mu \mathrm{m})$ in orange, bitumen in gray, $\mathrm{CH}_{4}$ ice $(100 \mu \mathrm{m})$ in magenta, $\mathrm{NH}_{3}$ ice $(100 \mu \mathrm{m})$ in brown, and $\mathrm{CO}_{2}$ ice $(10 \mu \mathrm{m})$ in light green) (for the resolution see references given in the text).

\subsection{Surface Morphology Considerations}

As noted earlier, the chemical diversity among the regions of interest retrieved from PCA and RT, may indicate that endogenic and/or exogenic processes acted in the area and resulted by depositing material of different chemical composition over the primary terrain. From what is also reported from other investigations of Titan VIMS data, the surface albedo behavior of the Hotei, Tui, and Sotra surrounding Rols appears similar to what is observed in some other areas. For example, the "Surrounding Sotra" surface albedo we obtain with our RT code is similar, in terms of value and shape, to the dunes area that is located at $7.5^{\circ} \mathrm{S}, 145^{\circ} \mathrm{W}$, while the "Surrounding Tui" albedo presents a similar shape to the albedo selected from a portion of the Belet "sand sea" (centered at $8^{\circ} \mathrm{S}, 264^{\circ} \mathrm{W}$ ). On the other hand, the anomalously $5 \mu \mathrm{m}$ bright material seems to exist only within Tui Regio and Hotei Regio locally. Such secondary material could have been deposited or washed out by exogenic (e.g., rain, wind, or deposits of evaporites) or endogenic processes (e.g., cryovolcanic deposits). However, the possibility for an exogenic origin of the areas is weakened by the absence of such surface heterogeneities in other locations where traces of rain have been observed. Turtle et al. [2011] monitored short-lived surface changes (within weeks) in a region at the southern boundary of Belet dunes field $\left(5^{\circ} \mathrm{N}, 255^{\circ} \mathrm{W}\right)$ that are attributed to the transition to northern spring resulting to methane rain at the equatorial latitudes. In the case of pluvial origin of the material covering our study areas, one would expect the area studied by Turtle et al. [2011] to present the same properties by showing an 
anomalous brightness at $5 \mu \mathrm{m}$, which is not the case from the studies of VIMS data. Persistence of the $5 \mu \mathrm{m}$ signature of Tui Regio and Hotei Regio over 2-3 years is another argument for excluding rain weathering. However, one cannot exclude the possibility of evaporite deposits which are much more stable. Hence, all of the exogenic processes cannot be ruled out.

The three study areas analyzed here have been considered cryovolcanic candidates [Lopes et al., 2013, and references therein]. Alternatively, work by Barnes et al. [2011] suggests that the features observed at Tui Regio are evaporitic deposits with noninternal connection. In addition, other studies focusing on Tui Regio and Hotei Regio describe the areas as paleolake clusters [Moore and Howard, 2010] and fluvial or lacustrine deposits [Moore and Pappalardo, 2011] indicating an exogenic origin. However, we cannot currently identify the type of process that formed these areas since cryovolcanism on Titan-even if the satellite seems to have the favorable conditions - is still an open issue and the so far acquired Cassini data do not provide conclusive evidence.

It would be very useful if laboratory experiments and albedo databases included various mixtures of possible candidates on Titan's surface that could be compared to the actual data, although it should be also noted that both DISR and VIMS observations are limited by their resolving powers ( 300 at best), preventing the detection of possible narrow, diagnostic spectral features within the methane windows. It is then no wonder that the question of Titan's surface chemical composition has not received a definitive answer to date and that the spectroscopic evidence that analyses such as ours are challenging to interpret. In the future, we plan to extend the application of our method to more time-dependent VIMS data and try to extract information on the chemical composition of the regions and their nature, as well as on their evolution with time. Combination of chemical composition inferences with morphological information from Cassini RADAR data should help further constraining the origin and nature of these regions, as well as other surface regions on Titan.

\section{Acknowledgments}

This research has been cofinanced by the European Union (European Social Fund-ESF) and Greek national funds through the Operational Program "Education and Lifelong Learning" of the National Strategic Reference Framework (NSRF)—Research Funding Program: Heracleitus II. Investing in knowledge society through the European Social Fund. The research was also partly supported by an appointment to the NASA Postdoctoral Program at the Jet Propulsion Laboratory, California Institute of Technology, administered by Oak Ridge Associated Universities through a contract with NASA. A.C., S.L.M., S.R., C.S., P.D., and M.H. acknowledge financial support from the French "Agence Nationale de la Recherche" (ANR Project: CH4@Titan and/or ANR project "APOSTIC" 11BS56002), France. Part of the research was carried out by A.S. at the National and Kapodistrian University of Athens, Department of Geology and Geoenvironment. We thank Jason W. Barnes and an anonymous referee for their thorough and constructive reviews of the manuscript.

\section{References}

Barnes, J. W., et al. (2005), A 5-micron-bright spot on Titan: Evidence for surface diversity, Science, 310, 92-95.

Barnes, J. W., et al. (2006), Cassini observations of flow-like features in western Tui Regio, Titan, Geophys. Res. Lett., 33, L16204, doi:10.1029/ 2006 GL026843.

Barnes, J. W., et al. (2007a), Near-infrared spectral mapping of Titan's mountains and channels, J. Geophys. Res., 112, E11006, doi:10.1029/ 2007JE002932.

Barnes, J. W., R. H. Brown, L. Soderblom, B. J. Buratti, C. Sotin, S. Rodriguez, S. Le Mouèlic, K. H. Baines, R. N. Clark, and P. D. Nicholson (2007b), Global-scale surface spectral variations on Titan seen from Cassini/VIMS, Icarus, 186, 242-258.

Barnes, J. W., et al. (2008), Spectroscopy, morphometry, and photoclinometry of Titan's dunefields from Cassini/VIMS, Icarus, 195, 400-414. Barnes, J. W., et al. (2011), Organic sedimentary deposits in Titan's dry lakebeds: Probable evaporite, Icarus, 216, $136-140$.

Bernard, J.-M., E. Quirico, O. Brissaud, G. Montagnac, B. Reynard, B. P. McMillan, P. Coll, M.-J. Nguyen, F. Raulin, and B. Schmitt (2006), Reflectance spectra and chemical structure of Titan's tholins: Application to the analysis of Cassini Huygens observations, Icarus, 185, 301-307.

Bieniawski, Z. T. (1989), Engineering Rock Mass Classifications: A Complete Manual for Engineers and Geologists in Mining, Civil, and Petroleum Engineering, pp. 40-47, Wiley-Interscience, Toronto, Canada.

Brown, R. H., et al. (2004), The Cassini visual and infrared mapping spectrometer (VIMS) investigation, Space Sci. Rev., 115, $111-168$.

Brown, R. H., J. W. Barnes, and H. J. Melosh (2011), On Titan's Xanadu region, Icarus, 214, 556-560.

Buratti, B. J., C. Sotin, K. Lawrence, R. H. Brown, S. Le Mouélic, J. M. Soderblom, J. Barnes, R. N. Clark, K. H. Baines, and P. D. Nicholson (2012), A newly discovered impact crater in Titan's Senkyo: Cassini VIMS observations and comparison with other impact features, Planet. Space Sci., 1, 18-25.

Burr, D. M., et al. (2013), Fluvial features on Titan: Insights from morphology and modeling, Geol. Soc. Am. Bull., 125, $299-321$.

Campargue, A., L. Wang, D. Mondelain, S. Kassi, B. Bézard, E. Lellouch, A. Coustenis, C. de Bergh, M. Hirtzig, and P. Drossart (2012), An empirical line list for methane in the $1.26-1.71 \mu \mathrm{m}$ region for planetary investigations $(\mathrm{T}=80-300 \mathrm{~K})$. Application to Titan, Icarus, 219 , $110-128$.

Coll, P., D. Coscia, N. Smith, M.-C. Gazeau, S. I. Ramirez, G. Cernogora, G. Israel, and F. Raulin (1999), Experimental laboratory simulation of Titan's atmosphere (aerosols and gas phase), Planet. Space Sci., 47, 1331-1340.

Coustenis, A., E. Lellouch, J. P. Maillard, and C. P. Mckay (1995), Titan's surface: Composition and variability from its near-infrared albedo, Icarus, 118, 87-104.

Coustenis, A., A. Salama, B. Schulz, S. Ott, E. Lellouch, T. H. Encrenaz, D. Gautier, and H. Feuchtgruber (2003), Titan's atmosphere from ISO mid-infrared spectroscopy, Icarus, 161, 383-403.

de Bergh, C., et al. (2012), Applications of a new set of methane line parameters to the modeling of Titan's spectrum in the $1.58 \mu \mathrm{m}$ window, Planet. Space Sci., 61, 85-98.

de Kok, R., et al. (2007), Oxygen compounds in Titan's stratosphere observed by Cassini CIRS, Icarus, 186, $354-363$.

Douté, S., and B. Schmitt (1998), A multilayer bidirectional reflectance model for the analysis of planetary surface hyperspectral images at visible and near-infrared wavelengths, J. Geophys. Res., 103, 31,367-31,390, doi:10.1029/98JE01894.

Elachi, C., et al. (2004), Radar: The Cassini Titan radar mapper, Space Sci. Rev., 115, 71-110.

Evans, K. F. (2007), SHDOMPPDA: A radiative transfer model for cloudy sky data assimilation, J. Atmos. Sci., 64, 3854-3864.

Fortes, A. D., P. M. Grindrod, S. K. Trickett, and L. Vocadlo (2007), Ammonium sulfate on Titan: Possible origin and role in cryovolcanism, Icarus, $188,139-153$. 
Fulchignoni, M., et al. (2005), In situ measurements of the physical characteristics of Titan's environment, Nature, 438, 785-791.

Furfaro, R., J. S. Kargel, J. I. Lunine, W. Fink, and M. P. Bishop (2010), Identification of cryovolcanism on Titan using fuzzy cognitive maps, Planet. Space Sci., 58, 761-779.

Gillespie, A. R. (1980), Digital techniques of image enhancement, in Remote Sensing of Geology, edited by B. S. Siegal and A. R. Gillespie, pp. 139-226, Wiley, New York.

Griffith, C. A., T. Owen, T. R. Geballe, J. Rayner, and P. Rannou (2003), Evidence for the exposure of water ice on Titan's surface, Science, 300, 628-630.

Griffith, C. A., L. Doose, M. G. Tomasko, P. F. Penteado, and C. See (2012), Radiative transfer analyses of Titan's tropical atmosphere, Icarus, 218 , 975-988.

Grundy, W. M., and B. Schmitt (1998), The temperature-dependent near- infrared absorption spectrum of hexagonal $\mathrm{H}_{2} \mathrm{O}$ ice, J. Geophys. Res. 103, 25,809-25,822, doi:10.1029/98JE00738.

Grundy, W. M., B. Schmitt, and E. Quirico (2002), The temperature-dependent spectrum of methane ice between 0.7 and $5 \mathrm{~mm}$ and opportunities for near-infrared remote thermometry, Icarus, 155, 486-496.

Head, J. W., et al. (2002), Evidence for Europa-like tectonic resurfacing styles on Ganymede, Geophys. Res. Lett., 29(24), 2151, doi:10.1029/ 2002GL015961.

Hirtzig, M., et al. (2013), Titan's surface and atmosphere from Cassini/VIMS data with updated methane opacity, Icarus, 226, 470-486. Jacquemart, D., E. Lellouch, B. Bézard, C. de Bergh, C. Coustenis, A. Lacome, B. Schmitt, and M. G. Tomasko (2008), New laboratory measurements of CH4 in Titan's conditions and a reanalysis of the DISR near-surface spectra at the Huygens landing site, Planet. Space Sci., 56, 613-623.

Jaumann, R. (1989), Spektrophotometrische Analyse der chemisch-mineralogischen Zusammensetzung lunarer Oberfla "chenmaterialien, PhD thesis, DLR-FB 89-40, 284, Faculty of Geosciences, Ludwig-Maximilian University, Munich.

Jolliffe, I. T. (2002), Principal Component Analysis, 2nd ed., Springer-Verlag, New York.

Jolliffe, I. T. (2005), Principal component analysis, in Encyclopedia of Statistics in Behavioral Science, 1580-1584, John Wiley \& Sons, New York. Khare, B. N., C. Sagan, and E. T. Arakawa (1984), Optical constants of organic tholins produced in a simulated Titanian atmosphere-From soft $\mathrm{X}$-ray to microwave frequencies, Icarus, 60, 127-137.

Kirk, R. L., E. Howington-Kraus, A. G. Hayes, R. M. C. Lopes, R. D. Lorenz, J. I. Lunine, K. L. Mitchell, E. R. Stofan, and S. D. Wall (2010), La Sotra y los otros: Topographic evidence for (and against) cryovolcanism on Titan, Eos Trans. AGU, 91(52), Fall Meet. Suppl., Abstract P22A-03.

Langhans, M. H., et al. (2012), Titan's fluvial valleys: Morphology, distribution, and spectral properties, Planet. Space Sci., 60, 34-51.

Le Corre, L., et al. (2009), Analysis of a cryolava flow-like feature on Titan, Planet. Space Sci., 57, 870-879.

Le Mouélic, S., et al. (2008), Mapping and interpretation of Sinlap crater on Titan using Cassini VIMS and RADAR data, J. Geophys. Res., 113, E04003, doi:10.1029/2007JE002965.

Le Mouélic, S., et al. (2012), Global mapping of Titan's surface using an empirical processing method for the atmospheric and photometric correction of Cassini/VIMS images, Planet. Space Sci., 73, 178-190.

Lellouch, E. (2006), Titan's zoo of clouds, Science, 311, 186-187.

Lellouch, E., B. Schmitt, A. Coustenis, and J.-G. Cuby (2004), Titan's 5-mm lightcurve, Icarus, 168, 209-214.

Lopes, R. M. C., et al. (2007), Cryovolcanic features on Titan's surface as revealed by the Cassini Titan radar mapper, Icarus, 186, 395-412.

Lopes, R. M. C., et al. (2010), Distribution and interplay of geologic processes on Titan from Cassini radar data, Icarus, 205, 540-558.

Lopes, R. M. C., et al. (2013), Cryovolcanism on Titan: New results from Cassini RADAR and VIMS, J. Geophys. Res. Planets, 118, 416-435, doi:10.1002/jgre.20062.

Lorenz, R. D., et al. (2006), The Sand Seas of Titan: Cassini RADAR Observations of Longitudinal Dunes.

Lorenz, R. D., et al. (2008), Fluvial channels on Titan: Meteorological paradigm and Cassini RADAR observations, Planet. Space Sci., 56, 1132-1144.

Lorenz, R. D., E. P. Turtle, B. Stiles, A. Le Gall, A. Hayes, O. Aharonson, C. A. Wood, E. Stofan, and R. Kirk (2011), Hypsometry of Titan, Icarus, 211, 699-706.

McCord, T. B., et al. (2006), Composition of Titan's surface from Cassini VIMS, Planet. Space Sci., 54, 1524-1539.

McCord, T. B., et al. (2008), Titan's surface: Search for spectral diversity and composition using the Cassini VIMS investigation, Icarus, 194, 212-242.

Mitri, G., M. T. Bland, A. P. Showman, J. Radebaugh, B. Stiles, R. M. C. Lopes, J. I. Lunine, and R. T. Pappalardo (2010), Mountains on Titan: Modeling and observations, J. Geophys. Res., 115, E10002, doi:10.1029/2010JE003592.

Moore, J. M., and A. D. Howard (2010), Are the basins of Titan's Hotei Regio and Tui Regio sites of former low latitude seas?, Geophys. Res. Lett., 37, L22205, doi:10.1029/2010GL045234.

Moore, J. M., and R. T. Pappalardo (2011), Titan: An exogenic world?, Icarus, 212, 790-806.

Negrão, A., A. Coustenis, E. Lellouch, J.-P. Maillard, P. Rannou, B. Schmitt, C. P. McKay, and V. Boudon (2006), Titan's surface albedo variations over a Titan season from near-infrared CFHT/FTS spectra, Planet. Space Sci., 54, 1225-1246.

Neish, C. D., R. L. Kirk, R. D. Lorenz, V. J. Bray, P. Schenk, B. Stiles, E. Turtle, K. Mitchell, A. Hayes, and the Cassini RADAR Team (2013), Crater topography on Titan: Implications for landscape evolution, Icarus, 223, 82-90.

Nelson, R. M., et al. (2009a), Saturn's Titan: Surface change, ammonia, and implications for atmospheric and tectonic activity, Icarus, 199, 429-441.

Nelson, R. M., et al. (2009b), Photometric changes on Saturn's Titan: Evidence for active cryovolcanism, Geophys. Res. Lett., 36, L04202, doi:10.1029/2008GL036206.

Niemann, H. B., et al. (2005), The abundances of constituents of Titan's atmosphere from the GCMS instrument on the Huygens probe, Nature, $438,779-784$.

Niemann, H. B., S. K. Atreya, J. Demick, D. Gautier, J. Haverman, D. Harpold, W. Kasprzak, J. Lunine, T. Owen, and F. Raulin (2010), Composition of Titan's lower atmosphere and simple surface volatiles as measured by the Cassini-Huygens probe gas chromatograph mass spectrometer experiment, J. Geophys. Res., 115, E12006, doi:10.1029/2010JE003659.

Porco, C. C., et al. (2004), Cassini imaging science: Instrument characteristics and anticipated scientific investigations at Saturn, Space Sci. Rev., $115,363-497$

Quirico, E., and B. Schmitt (1997), Near-infrared spectroscopy of simple hydrocarbons and carbon oxides diluted in solid $\mathrm{N}_{2}$ and as pure ices: Implications for Triton and Pluto, Icarus, 127, 354-378.

Quirico, E., S. Doute, B. Schmitt, C. De Bergh, D. P. Cruikshank, T. C. Owen, T. R. Geballe, and T. L. Roush (1999), Composition, physical state and distribution of ices at the surface of Triton, Icarus, 139, 159-178.

Radebaugh, J., R. D. Lorenz, R. L. Kirk, J. I. Lunine, E. R. Stofan, R. M. C. Lopes, S. D. Wall, and the Cassini Radar Team (2007), Mountains on Titan observed by Cassini Radar, Icarus, 192, 77-91.

Radebaugh, J., R. D. Lorenz, T. Farr, P. Paillou, C. Savage, and C. Spencer (2009), Linear dunes on Titan and Earth: Initial remote sensing comparisons, Geomorphology, 121, 122-132.

Radebaugh, J., et al. (2011), Regional geomorphology and history of Titan's Xanadu province, Icarus, 211, $672-685$. 
Rehman, S. (2010), Saudi Arabian geothermal energy resources-An update, in Proceedings of the World Geothermal Congress, pp. 1-6, International Geothermal Association, Bali, Indonesia.

Richards, J. A. (1994), Remote Sensing Digital Image Analysis: An Introduction, 340 pp., Springer, Berlin, Germany.

Rodriguez, S., et al. (2006), Cassini/VIMS hyperspectral observations of the Huygens landing site on Titan, Planet. Space Sci., 54, $1510-1523$. Rodriguez, S., et al. (2009), Global circulation as the main source of cloud activity on Titan, Nature, 459, 678-682.

Rodriguez, S., et al. (2011), Titan's cloud seasonal activity from winter to spring with Cassini/VIMS, Icarus, 216, 89-110.

Rodriguez, S., et al. (2014), Global mapping and characterization of Titan's dune fields with Cassini: Correlation between RADAR and VIMS observations, Icarus, 230, 168-179, doi:10.1016/j.icarus.2013.11.017.

Schmitt, B., E. Quirico. F. Trotta, and W. Grundy (1998), Optical properties of ices from UV to infrared, in Solar System Ices, Astrophys. Space Sci. Libr., vol. 227, edited by B. Schmitt, C. de Bergh, and M. Festou, pp. 199-240, Kluwer Acad., Dordrecht.

Singh, A., and A. Harrison (1985), Standardized principal components, Int. J. Remote Sens., 6, 883-896.

Soderblom, L. A., et al. (2007a), Topography and geomorphology of the Huygens landing site on Titan, Planet. Space Sci., 55, 2015-2024.

Soderblom, L. A., et al. (2007b), Correlations between Cassini VIMS spectra and RADAR SAR images: Implications for Titan's surface composition and the character of the Huygens Probe Landing Site, Planet. Space Sci., 55, 2025-2036.

Soderblom, L. A., et al. (2009), The geology of Hotei Regio, Titan: Correlation of Cassini VIMS and RADAR, Icarus, 204, 610-618.

Sohl, F., A. Solomonidou, F. W. Wagner, A. Coustenis, H. Hussmann, and D. Schulze-Makuch (2014), Structural and tidal models of Titan and inferences on cryovolcanism, J. Geophys. Res. Planets, 119, 1013-1036, doi:10.1002/2013JE004512.

Solomonidou, A., G. Bampasidis, M. Hirtzig, A. Coustenis, K. Kyriakopoulos, K. Seymour, E. Brastolis, and X. Moussas (2013), Morphotectonic features on Titan and their possible origin, Planet. Space Sci., 77, 104-117.

Sotin, C., et al. (2005), Release of volatiles from a possible cryovolcano from near-infrared imaging of Titan, Nature, 435, 786-789.

Sotin, C., et al. (2012), Observations of Titan's Northern lakes at $5 \mu \mathrm{m}$ : Implications for the organic cycle and geology, Icarus, 221, 768-786.

Stephan, K., C. A. Hibbitts, H. Hoffmann, and R. Jaumann (2008), Reduction of instrument-dependent noise in hyperspectral image data using the principal component analysis: Applications to Galileo NIMS data, Planet. Space Sci., 56, 406-419.

Stofan, E. R., et al. (2007), The lakes of Titan, Nature, 445, 61-64.

Tobie, G., O. Grasset, J. I. Lunine, A. Mocquet, and C. Sotin (2005), Titan's internal structure inferred from a coupled thermal-orbital model, Icarus, 175, 496-502.

Tobie, G., J. I. Lunine, and C. Sotin (2006), Episodic outgassing as the origin of atmospheric methane on Titan, Nature, 440, 61-64.

Tomasko, M. G., et al. (2005), Rain, winds and haze during the Huygens probe's descent to Titan's surface, Nature, 438, 765-778.

Tomasko, M. G., L. Doose, S. Engel, L. E. Dafoe, R. West, M. Lemmon, E. C. Karkoschka, and C. See (2008), A model of Titan's aerosols based on measurements made inside the atmosphere, Planet. Space Sci., 56, 669-707.

Turtle, E. P., et al. (2011), Rapid and extensive surface changes near Titan's equator: Evidence of April showers, Science, 331, $1414-1417$.

Vixie, G., et al. (2012), Mapping Titan's surface features within the visible spectrum via Cassini VIMS, Planet. Space Sci., 60, 52-61.

Wall, S. D., et al. (2009), Cassini RADAR images at Hotei Arcus and western Xanadu, Titan: Evidence for geologically recent cryovolcanic activity, Geophys. Res. Lett., 36, L04203, doi:10.1029/2008GL036415.

Wood, C. A., R. Lorenz, R. Kirk, R. M. C. Lopes, K. Mitchell, E. Stofan, and the Cassini RADAR Team (2010), Impact craters on Titan, Icarus, 206, 334-344.

Zarnecki, J. C., et al. (2005), A soft solid surface on Titan as revealed by the Huygens Surface Science Package, Nature, 438, 792-795.

Zhong, F., K. L. Mitchell, C. C. Hays, M. Choukroun, M. Barmatz, and J. S. Kargel (2009), The rheology of cryovolcanic slurries: Motivation and phenomenology of methanol-water slurries with implications for Titan, Icarus, 202, 607-619. 